Acta Crystallographica Section B

Structural

Science

ISSN 0108-7681

Tom Baikie, ${ }^{\mathrm{a} *}$ Stevin S. Pramana, ${ }^{a}$ Cristiano Ferraris, Yizhong Huang, ${ }^{a}$ Emma Kendrick, ${ }^{\mathrm{c}}$ Kevin S. Knight, ${ }^{\mathrm{d}}$ Zahara Ahmad ${ }^{\mathrm{a}}$ and T. J. White ${ }^{\mathrm{a}, \mathrm{e}}$

a Division of Materials Science and Engineering, Nanyang Technological University, Singapore,

b Laboratoire de Minéralogie et Cosmochimie du Muséum National d'Histoire Naturelle, UMRCNRS 7202, CP52, 61 Rue Buffon, 75005 Paris, France, ${ }^{\mathrm{c} C h e m i c a l}$ Sciences, University of Surrey, Guildford, Surrey, GU2 7XH, England, dISIS User Office, Building R3, Rutherford Appleton Laboratory, Chilton, Didcot, Oxfordshire, OX11 OQX, England, and ${ }^{\mathbf{e}}$ Centre for Advanced Microscopy, Australian National University, Canberra, ACT 2601, Australia

Correspondence e-mail: tbaikie@ntu.edu.sg

\title{
Polysomatic apatites
}

Certain complex structures are logically regarded as intergrowths of chemically or topologically discrete modules. When the proportions of these components vary systematically a polysomatic series is created, whose construction provides a basis for understanding defects, symmetry alternation and trends in physical properties. Here, we describe the polysomatic family $A_{5 N} B_{3 N} \mathrm{O}_{9 N+6} X_{N \delta}(2 \leq N \leq \infty)$ that is built by condensing $N$ apatite modules $\left(A_{5} B_{3} \mathrm{O}_{18} X_{\delta}\right)$ in configurations to create $B_{n} \mathrm{O}_{3 n+1}(1 \leq n \leq \infty)$ tetrahedral chains. Hydroxyapatite $\left[\mathrm{Ca}_{10}\left(\mathrm{PO}_{4}\right)_{6}(\mathrm{OH})_{2}\right]$ typifies a widely studied polysome where $N=2$ and the tetrahedra are isolated in $A_{10}\left(B \mathrm{O}_{4}\right)_{6} X_{2}$ compounds, but $N=3 A_{15}\left(B_{2} \mathrm{O}_{7}\right)_{3}\left(B \mathrm{O}_{4}\right)_{3} X_{3}$ (ganomalite) and $N=4 A_{20}\left(B_{2} \mathrm{O}_{7}\right)_{6} X_{4}$ (nasonite) are also known, with the $X$ site untenanted or partially occupied as required for charge balance. The apatite modules, while topologically identical, are often compositionally or symmetrically distinct, and an infinite number of polysomes is feasible, generally with the restriction being that an $A: B=5: 3$ cation ratio be maintained. The end-members are the $N=2$ polysome with all tetrahedra separated, and $N=\infty$, in which the hypothetical compound $A_{5} B_{3} \mathrm{O}_{9} X$ contains infinite, cornerconnected tetrahedral strings. The principal characteristics of a polysome are summarized using the nomenclature apatite( $A B X$ )-NS, where $A / B / X$ are the most abundant species in these sites, $N$ is the number of modules in the crystallographic repeat, and $S$ is the symmetry symbol (usually $H, T, M$ or $A$ ). This article examines the state-of-the-art in polysomatic apatite synthesis and crystallochemical design. It also presents $\mathrm{X}$-ray and neutron powder diffraction investigations for several polysome chemical series and examines the prevalence of stacking disorder by electron microscopy. These insights into the structure-building principles of apatite polysomes will guide their development as functional materials.

\section{Introduction}

Apatites are an important crystal family. In addition to the traditional use of phosphate varieties for bone and teeth replacement (Weiner \& Wagner, 1998) their diverse applications span hazardous waste fixation (Lutze \& Ewing, 1988), soil amendment (Manecki et al., 2000), laser materials (Payne et al., 1994) and clean energy (Nakayama et al., 1995). The archetype has the general formula $A_{4}^{F} A_{6}^{T}\left(B \mathrm{O}_{4}\right)_{6} X_{2}(A=$ large cations; $B=$ metals or metalloids; $X=$ anion) and a zeolitic topology where a $A_{4}^{F}\left(B \mathrm{O}_{4}\right)_{6}$ framework $(F)$ creates tunnels $(T)$, whose diameter adjusts to the filling characteristics of the $A_{6}^{T} X_{2}$ component. Less well known are the apatite polysomes ganomalite (Dunn et al., 1985; Carlson et al., 1997) and nasonite (Frondel \& Bauer, 1951; Giuseppetti et al., 1971).
Received 5 August 2009 Accepted 15 December 2009
(C) 2010 International Union of Crystallography Printed in Singapore - all rights reserved 
The concept of polysomatism was extensively developed by Thompson (1978) and Veblen (1991) for the crystallochemical analysis of rock-forming silicates and is a widely applied taxonomic principle for the description of condensed matter. The numerous polysome families include perovskite derivatives such as layered high $T_{\mathrm{c}}$ superconductors (Park \& Snyder, 1995), fluorite superstructures found in high-level nuclear ceramics (White et al., 1985), and $\beta$-alumina-hibonite materials that are encountered in superionic conductivity (Yao \& Kiemmer, 1967) and presolar mineralogy (Ireland, 1990; Nittler, 2003). In every case polysomes are derived by the regular alternation of geometrically commensurate, and usually compositionally distinct, slices that share a coherent interface lattice. Polysomatic descriptions accentuate common crystallographic features in families of related compounds (Hyde et al., 1979), illuminate linkages between structure and functionality (Mellini et al., 1987), and guide the optimization of physical properties in advanced materials (Leonyuk et al., 1999).

There is growing interest in apatites as functional materials enablers for clean energy, environmental, catalytic and electronic technologies, but a comprehensive assessment of polysome crystal chemistry has not been undertaken. This article consolidates our present understanding of apatite polysomatism, beginning with the formalization of building principles, followed by a review of definitive chemistries and structural analyses, and concluding with crystallographic refinements and microscopic examination of several new family members.

\subsection{Polysome construction and nomenclature}

Following the description of Povarennykh (1972) the apatite framework contains larger cations $\left(A^{F}\right)$ that are ideally coordinated to six oxygens in the disposition of $A^{F} \mathrm{O}_{6}$ metaprisms corner-connected to isolated $B_{4}$ tetrahedra. Twisting opposing (001) triangular prism faces by varying degrees $(\varphi)$ creates two apatite aristotypes where $\varphi=0^{\circ}$ leads to [001] face-sharing $A^{F} \mathrm{O}_{6}$ trigonal prism pillars, while $\varphi=60^{\circ}$ yields octahedral columns (White \& ZhiLi, 2003). The
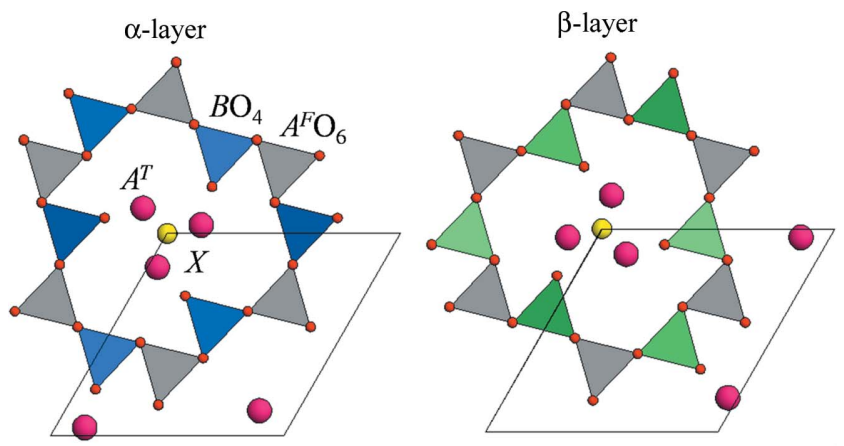

Figure 1

Schematic representation of $\alpha$ and $\beta, A_{5} B_{3} \mathrm{O}_{18} X_{2}$ apatite modules (assuming a hexagonal basal plane) that are related by $[001]_{\text {hex }} 60^{\circ}$ rotation twinning. The principal idealization is that the $A^{F} \mathrm{O}_{6}$ polyhedron is represented as a trigonal prism, but in real polysomes, twisting of the triangular faces through an angle $\varphi$ creates metaprisms. magnitude of $\varphi$ is regulated by the extent of channel filling with tunnel cations $\left(A^{T}\right)$ and anions $(X)$, such that when the $A_{3}^{T} X$ portion is relatively small or sub-stoichiometric the tunnel diameter contracts through larger metaprism twisting. In this scheme apatite is represented by the general formula $\left[A_{4}^{F}\right]\left[A_{6}^{T}\right]\left[\left(B \mathrm{O}_{4}\right)_{6}\right] X_{2}$. Generally, $\varphi$ adopts values ranging from $\sim 15$ to $25^{\circ}$, but in certain varieties the twist angle is smaller, as exemplified by hedyphane $\left[\mathrm{Ca}_{4}\right]\left[\mathrm{Pb}_{6}\right]\left[\left(\mathrm{AsO}_{4}\right)_{6}\right] \mathrm{Cl}_{2}$ (Rouse et al., 1984), where $\varphi=5.2^{\circ}$ because the tunnel not only accommodates a relatively large halide, but also the stereochemically active electron lone pairs of lead ions that strongly partition to the $A^{T}$ positions.

As the metaprism twist angles of apatite polysomes are usually quite acute, it is practical to adopt $\varphi=0^{\circ}$ as an idealized polysome module having the composition $A_{2}^{F} A_{3}^{T} B_{3} \mathrm{O}_{18} X$ and a thickness of $\sim 3.5 \AA$ with the disposition of trigonal prisms and tetrahedra shown in Figs. 1 and 2. These modules can occupy a hexagonal unit cell in two orientations, designated the $\alpha$ and $\beta$ layers, that are rotated $60^{\circ}$ with respect to each other, with condensation leading to the elimination of oxygen from the coincident lattice positions. Layers joined without rotation create corner-connected $B_{n} \mathrm{O}_{3 n+1}(n=\infty)$ tetrahedral strings that can be broken through introducing a rotated layer. Thus, if the modules are placed directly one upon the other in the sequence $\ldots \alpha(\alpha) \alpha \ldots$ the hypothetical compound $A_{2}^{F} A_{3}^{T} B_{3} \mathrm{O}_{9} X$ is created that contains continuous chains of corner-connected tetrahedra (Fig. $2 b$ ). In this case, nine $\mathrm{O}$ atoms are duplicated in the co-incident lattice - three from two triangular prism faces and one from each of the three tetrahedra at the conjoined module boundary. Alternatively, if every module is rotated $60^{\circ}$ (rotationally twinned) with respect to its neighbours in the order $\ldots \beta(\alpha \beta) \alpha \ldots$, six
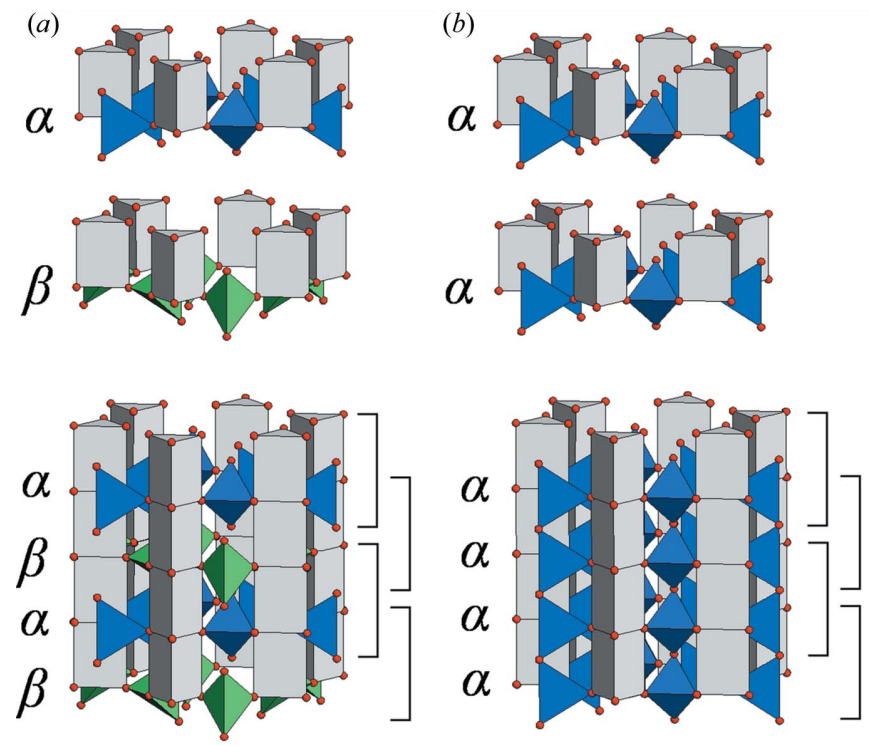

Figure 2

Stacking of $\alpha$ and $\beta$ modules for the construction of $\ldots \beta(\alpha \beta) \alpha \ldots$ apatite- $2 \mathrm{H}, A_{10}\left(B_{\mathrm{O}_{4}}\right)_{6} \mathrm{X}_{2}(a)$ and the hypothetical structure $\ldots \alpha(\alpha) \alpha \ldots$ apatite- $1 H, A_{5}\left(B_{3} \mathrm{O}_{9}\right) X(b)$ polysome end-members. The coincident lattice where condensation and elimination of oxygen takes place is emphasized by brackets. For clarity the $A^{T}$ and $X$ ions are not included. 
oxygen per layer pair are duplicated in the trigonal prisms, and the overall composition of the polysome is $A_{4}^{F} A_{6}^{T} B_{6} \mathrm{O}_{24} X_{2}$. In this configuration, the $\mathrm{BO}_{4}$ tetrahedra remain isolated and the familiar $\left[A_{4}^{F}\right]\left[A_{6}^{T}\right]\left[\left(B \mathrm{O}_{4}\right)_{6}\right] X_{2}$ apatite motif results as in $\left[\mathrm{Pb}_{4}\right]\left[\mathrm{Pb}_{6}\right]\left[\left(\mathrm{Si} / \mathrm{SO}_{4}\right)_{6}\right](\mathrm{Cl} / \mathrm{OH})_{2}$ mattheddleite (Fig. $2 a$ ).

An infinite number of arrangements intermediate to $\ldots \alpha(\alpha) \alpha \ldots$ and $\ldots \beta(\alpha \beta) \alpha \ldots$ are possible, and the ideal compositions of the apatite polysomes can be expressed as $A_{5 N} B_{3 N} \mathrm{O}_{9 N+6} X_{N \delta}(2 \leq N \leq \infty)$, where $N$ is the number of modules $\left(A_{5} B_{3} \mathrm{O}_{18} X_{\delta}\right)$ in the crystallographic repeat. All the tetrahedral sequences for the polysomes with $N=2$ to 8 are collated in Table 1 and Fig. 3, and evidentially, longer period structures can in principle adopt compositionally equivalent but structurally distinct configurations. The $A^{T}$ cations within the polysome tunnel also have discrete configurations such that for $N=2$ face-sharing columns of $A_{6}^{T}$ octahedra appear, while for $N=\infty$ these are transformed to trigonal prisms, with intermediate members showing mixed intergrowths

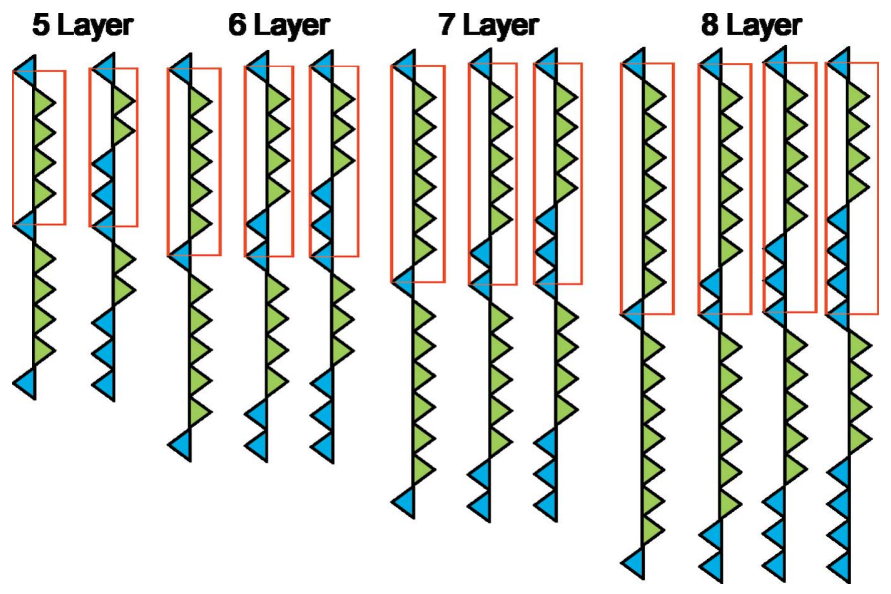

Figure 3

Possible tetrahedral stacking sequences for polysomes with $N>4$.
Table 1

Stacking sequences and compositions of polysomatic apatites.

\begin{tabular}{|c|c|c|c|}
\hline$N$ & $\begin{array}{l}\text { Crystallochemical } \\
\text { formulae }\end{array}$ & $\begin{array}{l}\text { Chemical } \\
\text { formulae }\end{array}$ & $\begin{array}{l}\text { Stacking } \\
\text { sequence }\end{array}$ \\
\hline 2 & $A_{10}\left(B \mathrm{O}_{4}\right)_{6} X_{2 \delta}$ & $A_{10} B_{6} \mathrm{O}_{24} X_{2 \delta^{\dagger}}$ & $\ldots \beta(\alpha \beta) \alpha \ldots$ \\
\hline 3 & $A_{15}\left(B_{2} \mathrm{O}_{7}\right)_{3}\left(B \mathrm{O}_{4}\right)_{3} X_{3 \delta}$ & $A_{15} B_{9} \mathrm{O}_{33} X_{3 \delta}$ & $\ldots \beta(\alpha \alpha \beta) \alpha \ldots$ \\
\hline 4 & $\begin{array}{l}A_{20}\left(B_{3} \mathrm{O}_{10}\right)_{3}\left(B \mathrm{O}_{3}\right)_{3} X_{4 \delta} \\
A_{20}\left(B_{2} \mathrm{O}_{7}\right)_{6} X_{4 \delta}\end{array}$ & $\begin{array}{l}A_{20} B_{12} \mathrm{O}_{42} X_{4 \delta} \\
A_{20} B_{12} \mathrm{O}_{42} X_{4 \delta} \S\end{array}$ & $\begin{array}{l}\ldots \beta(\alpha \alpha \alpha \beta) \alpha \ldots \\
\ldots \beta(\alpha \alpha \beta \beta) \alpha \ldots\end{array}$ \\
\hline 5 & $\begin{array}{l}A_{25}\left(B_{4} \mathrm{O}_{13}\right)_{3}\left(B \mathrm{O}_{4}\right)_{3} X_{5 \delta} \\
A_{25}\left(B_{3} \mathrm{O}_{10}\right)_{3}\left(B_{2} \mathrm{O}_{7}\right)_{3} X_{5 \delta}\end{array}$ & $\begin{array}{l}A_{25} B_{15} \mathrm{O}_{51} X_{5 \delta} \\
A_{25} B_{15} \mathrm{O}_{51} X_{5 \delta}\end{array}$ & $\begin{array}{l}\ldots \beta(\alpha \alpha \alpha \alpha \beta \beta) \alpha \ldots \\
\ldots \beta(\alpha \alpha \alpha \beta \beta) \alpha \ldots\end{array}$ \\
\hline 6 & $\begin{array}{l}A_{30}\left(B_{5} \mathrm{O}_{16}\right)_{3}\left(B \mathrm{O}_{4}\right)_{3} X_{6 \delta} \\
A_{30}\left(B_{4} \mathrm{O}_{13}\right)_{3}\left(B_{2} \mathrm{O}_{7}\right)_{3} X_{6 \delta} \\
A_{30}\left(B_{3} \mathrm{O}_{10}\right)_{6} X_{6 \delta}\end{array}$ & $\begin{array}{l}A_{30} B_{18} \mathrm{O}_{60} X_{6 \delta} \\
A_{30} B_{18} \mathrm{O}_{60} X_{6 \delta} \\
A_{30} B_{18} \mathrm{O}_{60} X_{6 \delta}\end{array}$ & $\begin{array}{l}\ldots \beta(\alpha \alpha \alpha \alpha \alpha \alpha) \alpha \\
\ldots \beta(\alpha \alpha \alpha \alpha \beta \beta) \alpha \\
\ldots \beta(\alpha \alpha \alpha \beta \beta \beta) \alpha .\end{array}$ \\
\hline 7 & $\begin{array}{l}A_{35}\left(B_{6} \mathrm{O}_{19}\right)_{3}\left(B \mathrm{O}_{4}\right)_{3} X_{7 \delta} \\
A_{35}\left(B_{5} \mathrm{O}_{16}\right)_{3}\left(B_{2} \mathrm{O}_{7}\right)_{3} X_{7 \delta} \\
A_{35}\left(B_{4} \mathrm{O}_{13}\right)_{3}\left(B_{3} \mathrm{O}_{10}\right)_{3} X_{7 \delta}\end{array}$ & $\begin{array}{l}A_{35} B_{21} \mathrm{O}_{69} X_{7 \delta} \\
A_{35} B_{21} \mathrm{O}_{69} X_{7 \delta} \\
A_{35} B_{21} \mathrm{O}_{69} X_{7 \delta}\end{array}$ & $\begin{array}{l}\ldots \beta(\alpha \alpha \alpha \alpha \alpha \alpha \beta) \alpha \ldots \\
\ldots \beta(\alpha \alpha \alpha \alpha \alpha \beta \beta) \alpha \ldots \\
\ldots \beta(\alpha \alpha \alpha \alpha \beta \beta \beta) \alpha \ldots\end{array}$ \\
\hline$\infty$ & $\begin{array}{l}A_{40}\left(B_{7} \mathrm{O}_{22}\right)_{3}\left(B \mathrm{O}_{4}\right)_{3} X_{8 \delta} \\
A_{40}\left(B_{6} \mathrm{O}_{19}\right)_{3}\left(B_{2} \mathrm{O}_{7}\right)_{3} X_{8 \delta} \\
A_{40}\left(B_{5} \mathrm{O}_{16}\right)_{3}\left(B_{3} \mathrm{O}_{10}\right)_{3} X_{8 \delta} \\
A_{40}\left(B_{4} \mathrm{O}_{13}\right)_{6} X_{8 \delta} \\
A_{5}\left(B_{2} \mathrm{O}_{0}\right) X_{8}\end{array}$ & $\begin{array}{l}A_{40} B_{24} \mathrm{O}_{78} X_{8 \delta} \\
A_{40} B_{24} \mathrm{O}_{78} X_{8 \delta} \\
A_{40} B_{24} \mathrm{O}_{78} X_{8 \delta} \\
A_{40} B_{24} \mathrm{O}_{78} X_{8 \delta} \\
A_{5} B_{2} \mathrm{O}_{9} X_{8}\end{array}$ & $\begin{array}{l}\ldots \beta(\alpha \alpha \alpha \alpha \alpha \alpha \alpha \beta) \alpha \ldots \\
\ldots \beta(\alpha \alpha \alpha \alpha \alpha \alpha \beta \beta) \alpha \ldots \\
\ldots \beta(\alpha \alpha \alpha \alpha \alpha \beta \beta \beta) \alpha \ldots \\
\ldots \beta(\alpha \alpha \alpha \alpha \beta \beta \beta \beta) \alpha \ldots\end{array}$ \\
\hline$\infty$ & & $B_{3}($ & $\alpha(\alpha) \alpha$. \\
\hline
\end{tabular}

$\dagger$ Apatite. $\$$ Ganomalite. § Nasonite.
(O'Keeffe \& Hyde, 1985). The $X$ anions are located in the centres of the $A_{3}^{T}$ triangles if small enough, but more often are displaced along the module stacking direction to partially occupied crystallographic sites (Fig. 4).

The silicate mineral ganomalite is an example of the $N=3$ polysome with the module sequence $\ldots \beta(\alpha \alpha \beta) \alpha \ldots$ and ideal formula $\left[A_{6}^{F}\right]\left[A_{9}^{T}\right]\left[\left(B_{2} \mathrm{O}_{7}\right)_{3}\left(B \mathrm{O}_{4}\right)_{3}\right] X_{3}$. The composition is $\mathrm{Pb}_{9} \mathrm{Ca}_{5.44} \mathrm{Mn}_{0.56} \mathrm{Si}_{9} \mathrm{O}_{33}$ (Carlson et al., 1997) that when rearranged as $\left[\mathrm{Ca}_{5.44} \mathrm{Mn}_{0.56}\right]\left[\mathrm{Pb}_{9}\right]\left[\left(\mathrm{Si}_{2} \mathrm{O}_{7}\right)_{3}\left(\mathrm{SiO}_{4}\right)_{3}\right] \square_{3}$ emphasizes the common crystallochemical characteristics of apatite polysomes (Fig. 5a). Strong, and in this case complete, partitioning of lead to the tunnel is often observed in the polysomes, as in the absence of $X$ anions the lone-pair electrons of $\mathrm{Pb}^{2+}$ occupy the space released. The $A^{F} \mathrm{O}_{6}$ metaprisms at the $\alpha \beta$ boundaries are fully occupied by larger $\mathrm{Ca}^{2+}(1.00 \AA)$ and have a relatively large twist angle of $\varphi=$ $17.2^{\circ}$, while those adjacent to the $\mathrm{Si}_{2} \mathrm{O}_{7} \alpha \alpha$ modules contain smaller $\mathrm{Mn}^{2+} \quad(0.83 \AA)$ with the $\left(\mathrm{Mn}_{0.56} \mathrm{Ca}_{0.44}\right) \mathrm{O}_{6}$ trigonal prism having $\varphi=0^{\circ}$ (Fig. 6b). In common with all $N$ odd structures, the highest possible symmetry space group is ideally $P \overline{6}$.

Nasonite with $N=4$ adopts the configuration $\ldots \beta(\alpha \alpha \beta \beta) \alpha \ldots$, where the ideal formulation $\left.\left[A_{8}^{F}\right]\left[A_{12}^{T}\right]\left[\left(B_{2} \mathrm{O}_{7}\right)_{6}\right)\right] X_{4}$ is mimicked compositionally as $\left.\left[\mathrm{Ca}_{8}\right]\left[\mathrm{Pb}_{12}\right]\left[\left(\mathrm{Si}_{2} \mathrm{O}_{7}\right)_{6}\right)\right] \mathrm{Cl}_{4}$ (Giuseppetti et al., 1971) in the type mineral (Figs. $5 c$ and $6 c$ ). Again, lead enters the tunnel exclusively, but unlike ganomalite the channel accommodates chlorine, in addition to the lone-pair electrons,
Figure 4

Arrangement of the $A^{T}$ octahedra and/or trigonal prisms in (a) apatite-2S, where a small $X$ anion is positioned in the $A_{3}^{T}$ triangle, $(b)$ ganomalite $-3 S$ with the $X$-site vacant and (c) nasonite- $4 S$ that contains a large $X$ anion centred in the $A_{6}^{T}$ polyhedra. 
(a)

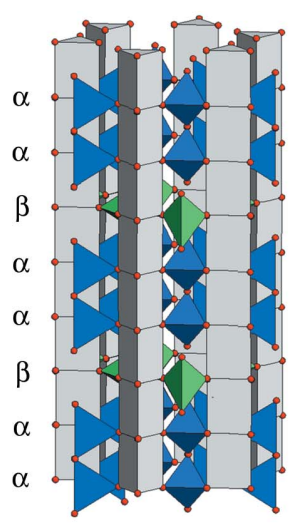

$\ldots \beta(\alpha \alpha \beta) \alpha \ldots$ (b)

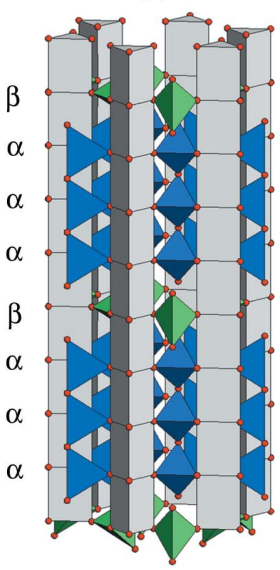

... $\beta(\alpha \alpha \alpha \beta) \alpha \ldots$ (c)

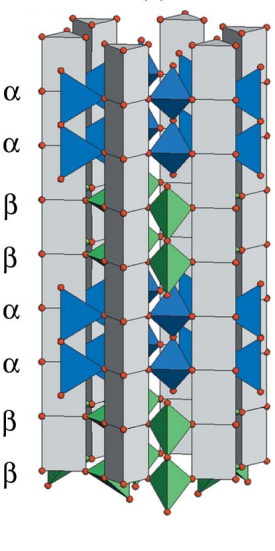

$\ldots \beta(\alpha \alpha \beta \beta) \alpha \ldots$

Figure 5

Polysome stacking sequences for $(a) N=3,(b) N=4$ without a centre of symmetry and $(c) N=4$ with a centre of symmetry.

and must expand almost completely across both the $\alpha \beta$ and $\alpha \alpha$ module boundaries leading to $\varphi=6.2$ and $0^{\circ}$. As this polysome has $N$ even the space group is ideally $P 6_{3} / m$. For $N=4$ the alternate module arrangement ... $\beta(\alpha \alpha \alpha \beta) \alpha \ldots$ (Fig. $5 b)$ is possible in principle, but has not been verified in apatite polysomes, possibly because $\mathrm{Si}_{3} \mathrm{O}_{10}$ chains prove less stable than $\mathrm{Si}_{2} \mathrm{O}_{7}$ owing to the high electrostatic repulsions between the closely spaced $\mathrm{Si}^{4+}$ ions. Clearly, the longer the stacking repeat, the greater the possibility for polysomatic intergrowth.

A nomenclature to describe the essential characteristics of the polysomes has been adapted from the recommendations of the Commission on New Minerals, Nomenclature and Classification (CNMNC) for the naming of apatite minerals (Pasero et al., 2010). ${ }^{\mathbf{1}}$ In this scheme, naming takes the general form apatite- $(A B X)-N S$; the generic family appellation can be replaced by the specific mineral if known for a particular composition; $(A B X)$ are the most abundant constituents on these sites; $N$ is the number of modules in the crystallographic repeat and $S$ the lattice symmetry. Thus, for $N=2$ polysomes (with conventional apatite structures) the hexagonal vanadate $\mathrm{Pb}_{10}\left(\mathrm{VO}_{4}\right)_{6} \mathrm{Cl}_{2}$ would be written as vanadinite- $(\mathrm{Pb} \mathrm{V} \mathrm{Cl})-2 \mathrm{H}$ (Dai \& Hughes, 1989), monoclinic chlorapatite $\mathrm{Ca}_{10}\left(\mathrm{PO}_{4}\right)_{6} \mathrm{Cl}_{2}$ as chlorapatite-(Ca P Cl)-2M (Mackie et al., 1972), while triclinic svabite $\mathrm{Ca}_{10}\left(\mathrm{AsO}_{4}\right)_{6} \mathrm{~F}_{2}$ is svabite-( $\left.\mathrm{Ca} \mathrm{As} \mathrm{F}\right)-2 A$ (Baikie et al., 2007). By extension, the minerals ganomalite and nasonite described above are ganomalite-( $\mathrm{Pb} \mathrm{Si} \square)-3 H$ (Carlson et al., 1997) and nasonite-(Pb Si Cl)-4H (Giuseppetti et al., 1971).

\subsection{Polysome chemistry}

1.2.1. $\boldsymbol{N}=2$. The crystal chemistry of $\ldots \beta(\alpha \beta) \alpha \ldots$ apatite$2 S$ structures is diverse and there is little need to add to several

\footnotetext{
1 This nomenclature was reviewed by the IMA Commission to address inconsistencies in naming apatite minerals (see also Nickel \& Mandarino, 1987).
}

extensive reviews (White et al., 2005; Hughes et al., 1989; Pan \& Fleet, 2002; Piccoli \& Candela, 2002). Of the total number of chemical end-members somewhat less than $60 \%$ of this polysome are hexagonal $P 6_{3} / \mathrm{m}$, while a further third crystal- (a)

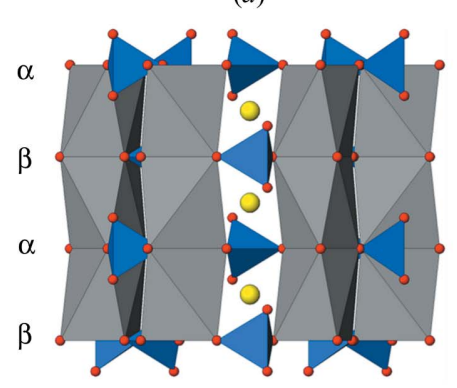

(b)

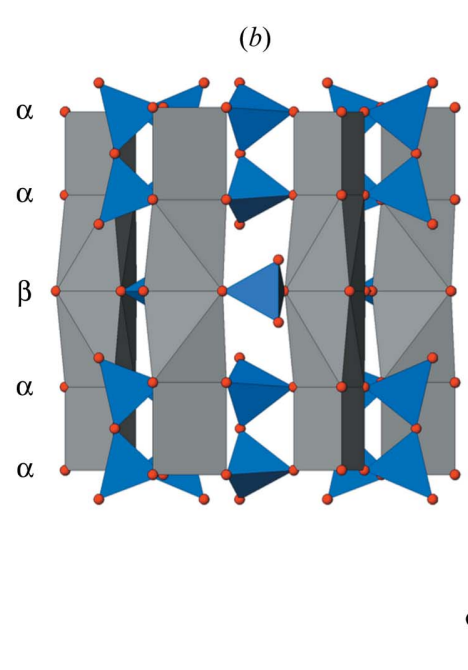

(c)

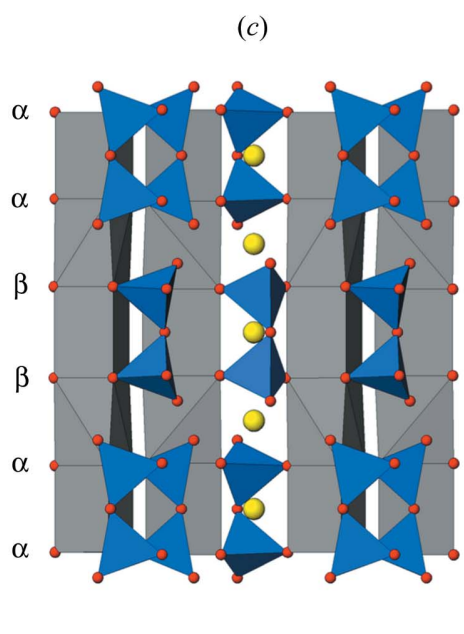

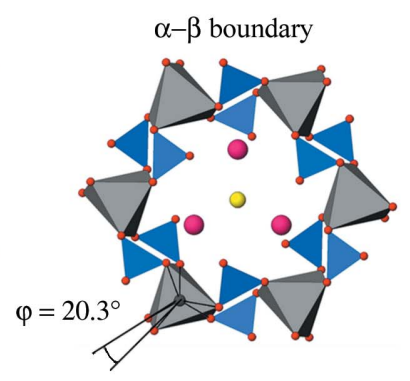

$\alpha-\alpha$ boundary
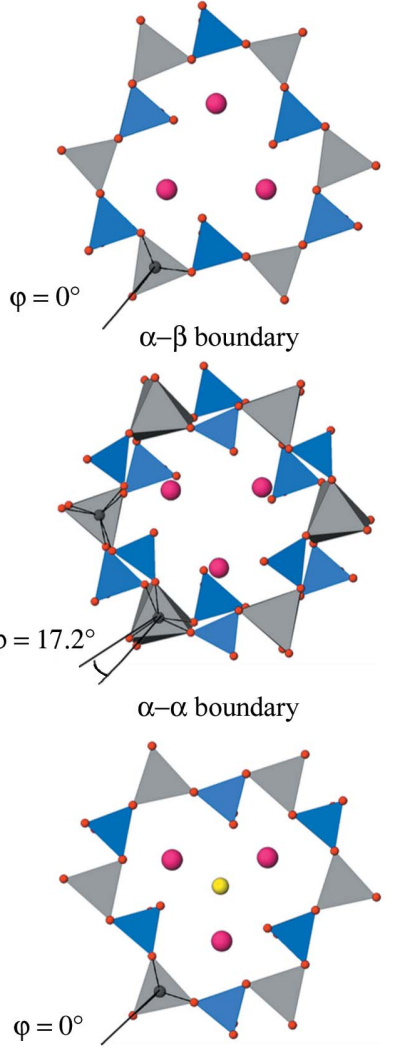

$\alpha-\beta$ boundary

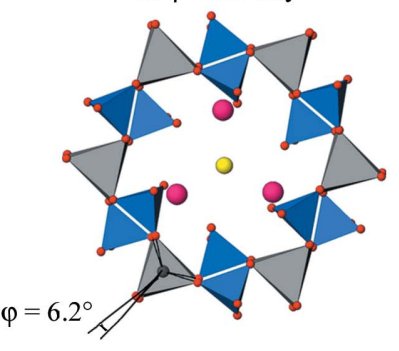

Figure 6

Polyhedral drawings shown in [100] (left) and [001] (right) of (a) $N=2$ $\mathrm{Pb}_{10}\left(\mathrm{Si} / \mathrm{SO}_{4}\right)_{6} \mathrm{Cl}_{2-x}(\mathrm{OH})_{x}$ mattheddleite- $(\mathrm{Pb} \mathrm{Si} / \mathrm{S} \mathrm{Cl})-2 \mathrm{H},(b) \quad N=3$ $\mathrm{Ca}_{5.44} \mathrm{Mn}_{0.56} \mathrm{~Pb}_{9}\left(\mathrm{Si}_{2} \mathrm{O}_{7}\right)_{3}\left(\mathrm{SiO}_{4}\right)_{3} \square_{3}$ ganomalite $-(\mathrm{Pb} \mathrm{Si} \square)-3 H$ and $(c) N=$ $4 \mathrm{Ca}_{8} \mathrm{~Pb}_{12}\left(\mathrm{Si}_{2} \mathrm{O}_{7}\right)_{6} \mathrm{Cl}_{4}$ nasonite $-(\mathrm{Ca} / \mathrm{Pb} \mathrm{Si} \mathrm{Cl})-4 H$ with associated twist angles of the individual modules. The $A^{F} \mathrm{O}_{6}$ twist angles across $(\alpha \alpha)$ boundaries are always smaller than $(\alpha \beta)$ boundaries. 
Table 2

Reported lattice parameters for $N \geq 3$ apatite polysomes (e.s.d.s shown where reported).

\begin{tabular}{|c|c|c|}
\hline Phase & Crystal data $(\AA)$ & Reference \\
\hline $\mathrm{Ca}_{5} \mathrm{MnPb}_{9}\left(\mathrm{Si}_{2} \mathrm{O}_{7}\right)_{3}\left(\mathrm{SiO}_{4}\right)_{3}$ & $a=9.82, c=10.13$ & Dunn et al. (1985) \\
\hline $\mathrm{Ca}_{5.44} \mathrm{Mn}_{0.56}\left(\mathrm{Si}_{2} \mathrm{O}_{7}\right)_{3}\left(\mathrm{SiO}_{4}\right)_{3}$ & $a=9.8456(3), c=10.1438$ & Carlson et al. (1997) \\
\hline $\mathrm{Pb}_{15}\left(\mathrm{Ge}_{2} \mathrm{O}_{7}\right)_{3}\left(\mathrm{GeO}_{4}\right)_{3}$ & $a=10.19, c=10.624$ & Kay et al. (1975) \\
\hline $\mathrm{Ca}_{6} \mathrm{~Pb}_{9}\left(\mathrm{Si}_{2} \mathrm{O}_{7}\right)_{3}\left(\mathrm{SiO}_{4}\right)_{3}$ & $a=9.849(2), c=10.152(2)$ & Engel (1972) \\
\hline $\mathrm{Pb}_{9} \mathrm{Bi}_{3} \mathrm{Na}_{3}\left(\mathrm{Si}_{2} \mathrm{O}_{7}\right)_{3}\left(\mathrm{SiO}_{4}\right)_{3}$ & $a=9.876(1), c=10.175(1)$ & Engel (1972) \\
\hline $\mathrm{Cd}_{6} \mathrm{~Pb}_{9}\left(\mathrm{Si}_{2} \mathrm{O}_{7}\right)_{3}\left(\mathrm{SiO}_{4}\right)_{3}$ & $a=9.810(4), c=10124$ & Engel (1972) \\
\hline $\mathrm{Cd}_{6} \mathrm{~Pb}_{9}\left(\mathrm{Ge}_{2} \mathrm{O}_{7}\right)_{3}\left(\mathrm{GeO}_{4}\right)_{3}$ & $a=10.104(1), c=10.379(1)$ & Engel (1972) \\
\hline $\mathrm{Pb}_{9} \mathrm{Bi}_{3} \mathrm{Na}_{3}\left(\mathrm{Ge}_{2} \mathrm{O}_{7}\right)_{3}\left(\mathrm{GeO}_{4}\right)_{3}$ & $a=10.084(1), c=10.398(1)$ & Engel (1972) \\
\hline $\mathrm{Pb}_{15}\left(\mathrm{Ge}_{2} \mathrm{O}_{7}\right)_{3}\left(\mathrm{TiO}_{4}\right)_{3}$ & $a=10.294(7), c=10.730$ & $\begin{array}{l}\text { Goswami, Mahapatra \& } \\
\text { Choudhary (1998) }\end{array}$ \\
\hline $\mathrm{Ca}_{015} \mathrm{~Pb}_{14.85} \mathrm{Ge}_{75} \mathrm{Ti}_{15} \mathrm{O}_{33}$ & $a=10.2574, c=10.6706$ & Goswami et al. (1998b) \\
\hline $\mathrm{Sr}_{0.15} \mathrm{~Pb}_{14.85} \mathrm{Ge}_{7.5} \mathrm{Ti}_{1.5} \mathrm{O}_{33}$ & $a=10.2625, c=10.6772$ & Goswami et al. (1998b) \\
\hline $\mathrm{Sr}_{0.15} \mathrm{~Pb}_{14.85} \mathrm{Ge}_{7.5} \mathrm{Ti}_{1.5} \mathrm{O}_{33}$ & $a=10.2727, c=10.6905$ & Goswami et al. (1998b) \\
\hline $\mathrm{Pb}_{15}\left(\mathrm{Ge}_{2} \mathrm{O}_{7}\right)_{3}\left(\mathrm{ZrO}_{4}\right)_{3}$ & $a=10.2818, c=10.7168$ & Goswami et al. (1997) \\
\hline $\mathrm{Ca}_{06} \mathrm{~Pb}_{144}\left(\mathrm{Ge}_{2} \mathrm{O}_{7}\right)_{3}\left(\mathrm{GeO}_{4}\right)_{3}$ & $a=10.293(8), c=10.665(9)$ & Misra et al. (1995) \\
\hline $\mathrm{Sr}_{0.3} \mathrm{~Pb}_{14.7}\left(\mathrm{Ge}_{2} \mathrm{O}_{7}\right)_{3}\left(\mathrm{GeO}_{4}\right)_{3}$ & $a=10.229(5), c=10.67(4)$ & Misra et al. (1998) \\
\hline $\mathrm{Sr}_{0.6} \mathrm{~Pb}_{14.4}\left(\mathrm{Ge}_{2} \mathrm{O}_{7}\right)_{3}\left(\mathrm{GeO}_{4}\right)_{3}$ & $a=10.220(8), c=10.661(4)$ & Misra et al. (1998) \\
\hline $\mathrm{Sr}_{09} \mathrm{~Pb}_{141}\left(\mathrm{Ge}_{2} \mathrm{O}_{7}\right)_{3}\left(\mathrm{GeO}_{4}\right)_{3}$ & $a=10.216(1), c=10.654(3)$ & Misra et al. (1998) \\
\hline $\mathrm{Ba}_{0.3} \mathrm{~Pb}_{14.7}\left(\mathrm{Ge}_{2} \mathrm{O}_{7}\right)_{3}\left(\mathrm{GeO}_{4}\right)_{3}$ & $a=10.2465, c=10.6758$ & Choudhary \& Misra (1998) \\
\hline $\mathrm{Ba}_{06} \mathrm{~Pb}_{144}\left(\mathrm{Ge}_{2} \mathrm{O}_{7}\right)_{3}\left(\mathrm{GeO}_{4}\right)_{3}$ & $a=10.2507, c=10.6790$ & Choudhary \& Misra (1998) \\
\hline $\mathrm{Ba}_{0.9} \mathrm{~Pb}_{14.1}\left(\mathrm{Ge}_{2} \mathrm{O}_{7}\right)_{3}\left(\mathrm{GeO}_{4}\right)_{3}$ & $a=10.2540, c=10.6847$ & Choudhary \& Misra (1998) \\
\hline $\mathrm{Pb}_{14.7} \mathrm{Bi}_{0.3} \mathrm{Ge}_{8.7} B_{0.3} \mathrm{O}_{33}$ & $a=10.219(1), c=10.667(2)$ & Otto \& Loster (1993) \\
\hline $\mathrm{Pb}_{14.4} \mathrm{Bi}_{0.6} \mathrm{Ge}_{8.4} \mathrm{~B}_{0.6} \mathrm{O}_{33}$ & $a=10.212(2), c=10.664(2)$ & Otto \& Loster (1993) \\
\hline $\mathrm{Ca}_{8} \mathrm{~Pb}_{12}\left(\mathrm{Si}_{2} \mathrm{O}_{7}\right)_{6} \mathrm{Cl}_{4}$ & $a=10.08, c=13.27$ & Giuseppetti et al. (1971) \\
\hline
\end{tabular}

atomic displacement parameters (ADPs) and unreasonable bond lengths. A more recent single-crystal study (Carlson et al., 1997) of ganomalite-( $\mathrm{Pb} \mathrm{Si} \square)-3 H$ from the same locality yielded $P \overline{6}$ and the chemical formula $\left[\mathrm{Ca}_{5.44} \mathrm{Mn}_{0.56}\right]\left[\mathrm{Pb}_{9}\right]\left[\left(\mathrm{Si}_{2} \mathrm{O}_{7}\right)_{3}\left(\mathrm{SiO}_{4}\right)_{3}\right] \square_{3}$. This study found that $P 3$ offered no improvement in the refinement residuals.

Generally, synthetic $N=3$ polysomes are less well characterized than their $N=2$ counterparts, although $\left[\mathrm{Pb}_{6}\right]\left[\mathrm{Pb}_{9}\right]\left[\left(\mathrm{Ge}_{2} \mathrm{O}_{7}\right)_{3}\left(\mathrm{GeO}_{4}\right)_{3}\right] \square_{3}$ has received significant attention because of its ferroelectric and pyroelectric functionality, and reversible optical activity (Iwata, 1977; Iwata et al., 1973; Kay et al., 1975; Iwasaki et al., 1971; Iwasaki, Miyazawa et al., 1972; Iwasaki, Sugii et al., 1972; Nanamatsu et al., 1971; Wu et al., 2004; Newnham et al., 1973). As for the natural species, there was initial debate regarding the space-group assignment, with ganomalite(Pb Ge $\square$ )-3H first reported in $P \overline{6}$ (Newnham et al., 1973). However, a re-determination suggested $P 3$ ganomalite-( $\mathrm{Pb}$ Ge $\square$ )-3T (Iwata et al., 1973), later corroborated by powder neutron diffraction (Kay et al., 1975). A separate

lize in hexagonal and trigonal subgroups $\left(P 6_{3}, P \overline{6}\right.$ and $\left.P \overline{3}\right)$, with the balance monoclinic $\left(P 2_{1} / m\right.$ or $P 2_{1}$; Elliott et al., 1973) or triclinic $(P \overline{1}$; Baikie et al., 2007). Almost every element in the periodic table can be accommodated in apatite- $2 S$. In addition, oxidized and reduced varieties exist with the $B$ cations in triangular [e.g. finnemanite $\mathrm{Pb}_{10}\left(\mathrm{AsO}_{3}\right)_{6} \mathrm{Cl}_{2}$; Baikie et al., 2008] and penta-coordination [e.g. $\mathrm{Ba}_{10}\left(\mathrm{ReO}_{5}\right)_{6} \mathrm{Cl}_{2}$; Besse et al., 1979], rather than $B_{4}$ tetrahedra; hybrid varieties such as $\left[\mathrm{Ca}_{9} \mathrm{Na}_{0.5}\right]\left[\left(\mathrm{PO}_{4}\right)_{4.5}\left(\mathrm{CO}_{3}\right)_{1.5}\right](\mathrm{OH})_{2}$ (Feki et al., 1999) and $\left[\mathrm{La}_{10}\right]\left[\left(\mathrm{GeO}_{4}\right)_{5}\left(\mathrm{GeO}_{5}\right)\right] \mathrm{O}_{2}$ (Pramana et al., 2007) have been described. Non-stoichiometry can appear in the framework (e.g. $\left[\mathrm{La}_{3.33}\right]\left[\mathrm{La}_{6}\right]\left(\mathrm{SiO}_{4}\right)_{6} \mathrm{O}_{2}$; Sansom et al., 2001) or tunnel [e.g. $\mathrm{Cd}_{10}\left(\mathrm{PO}_{4}\right)_{6} \mathrm{Br}(\mathrm{I})_{2}-\delta$; Alberius-Henning et al., 2000], which gives rise to modulated structures, or the common $P 2_{1} / b$ variant with inter-channel order correlation of the statistically occupied $X$ position (Bauer \& Klee, 1993). Transition metal ions can also be located in the $X$ sites, for example in $A_{10}\left(\mathrm{PO}_{4}\right)_{6} M_{x} \mathrm{O}_{y} \mathrm{H}_{z}[A=$ alkaline earth metal; $M=$ $\mathrm{Cu}$ (Kazin et al., 2003; Baikie et al., 2009), Ni, Co Zn (Kazin et al., 2007)]. Furthermore, cation $\left[\right.$ e.g. $\left[\mathrm{Nd}_{3.33}\right]\left[\mathrm{La}_{2} \mathrm{Nd}_{4}\right]-$ $\left.\left(\mathrm{SiO}_{4}\right)_{6} \mathrm{O}_{2}\right]$; Malinovskii et al., 1990] and anion [e.g. $\mathrm{Ca}_{10}\left(\mathrm{PO}_{4}\right)_{6} \mathrm{I}_{2 / 3} \mathrm{O}_{2 / 3}$; Alberius-Henning et al., 1999] ordering can yield superstructures, which retain bimodular periodicity along the stacking direction and modify translational periodicity in $(00 l)$.

1.2.2. $N=3$. The mineral ganomalite from Långban, first described by Nordenskiöld (1876, 1877), was erroneously identified as the hydroxyl analogue of nasonite, i.e. $\mathrm{Ca}_{8} \mathrm{~Pb}_{12}\left(\mathrm{Si}_{2} \mathrm{O}_{7}\right)_{3}(\mathrm{OH})_{4}$. Ganomalite was subsequently redefined as $\left[\mathrm{Ca}_{5} \mathrm{Mn}\right]\left[\mathrm{Pb}_{9}\right] \mathrm{Si}_{9} \mathrm{O}_{33}$ (Dunn et al., 1985) with $P 3$ as the most likely space group, since refinements in $P \overline{6}$ gave large positional errors, unrealistic site occupancies, non-physical study re-confirmed $P 3$ for $\mathrm{Pb}_{15}\left(\mathrm{Ge}_{2} \mathrm{O}_{7}\right)_{3}\left(\mathrm{GeO}_{4}\right)_{3}$ and the isomorphous material $\mathrm{Pb}_{15}\left(\mathrm{Ge}_{2} \mathrm{O}_{7}\right)_{3}\left(\mathrm{SiO}_{4}\right)_{3}$ from the X-ray extinction conditions (Iwasaki, Miyazawa et al., 1972). At room temperature these materials are ferroelectric, however, above the Curie temperature $(\sim 450 \mathrm{~K})$, changes in X-ray extinction suggested the paraelectric phases undergo a transformation to $P \overline{6}$, as subsequently confirmed by a neutron study (Iwata, 1977). The trigonal to hexagonal transition was attributed to the twisting and displacement of the $\mathrm{Ge}_{2} \mathrm{O}_{7}$ double tetrahedra. The influence of substitutions over the $\mathrm{Pb}$ and $\mathrm{Ge}$ sites on the dielectric properties of $\mathrm{Pb}_{15} \mathrm{Ge}_{3} \mathrm{O}_{33}$ has been studied. For example, polycrystalline and single-phase $\mathrm{Pb}_{15-x} A_{x} \mathrm{Ge}_{9-y} B_{y} \mathrm{O}_{33}, A=\mathrm{Ca}$ (Misra et al., 1995; Goswami et al., 2001), Sr (Misra et al., 1998), Ba (Choudhary \& Misra, 1998) and Cd (Engel, 1972), B = Si (Eysel et al., 1973; Iwasaki, Miyazawa et al., 1972), Ti (Goswami, Mahapatra et al., 1998; Goswami, Choudhary et al., 1998b) and Zr (Goswami et al., 1997, 1998a), and more recently, coupled aliovalent substitutions of $\mathrm{Nd}^{3+} / \mathrm{K}^{+}$(Wazalwar \& Katpatal, 2001, 2002) or $\mathrm{Bi}^{3+} /$ $\mathrm{Cs}^{+}$(Otto et al., 1980) for $\mathrm{Pb}^{2+}$ have been reported (see also Table 2). Whilst the ganomalite polysome persists upon doping, the introduction of smaller cations at the $\mathrm{Pb}$ sites decreases the ferroelectric transition temperature and appropriate substitutions over $\mathrm{Pb}$ and $\mathrm{Ge}$ sites gave $243 \leq T_{\mathrm{c}}$ $\leq 573 \mathrm{~K}$. However, detailed crystallographic investigations were not carried out and only lattice parameters were reported. $B$-site substitutions with cations of a different charge, and without counter-ion substitution at the $A$ site, have been attempted but lead to the formation of lacunar-type apatite- $2 H$ with the tunnel site $X$ anions absent, e.g. $\mathrm{Pb}_{10}\left(\mathrm{GeO}_{4}\right)_{4}\left(\mathrm{CrO}_{4}\right)_{2} \square_{2} \quad$ (Engel \& Deppisch, 1988), $\mathrm{Pb}_{10}\left(\mathrm{GeO}_{4}\right)_{4}\left(\mathrm{SO}_{4}\right)_{2} \square_{2} \quad$ (Engel \& Deppisch, 1988), 
$\mathrm{Pb}_{10}\left(\mathrm{GeO}_{4}\right)_{2}\left(\mathrm{VO}_{4}\right)_{4} \square_{2}$ (Ivanov, 1990) and $\mathrm{Pb}_{10}\left(\mathrm{SiO}_{4}\right)_{2^{-}}$ $\left(\mathrm{VO}_{4}\right)_{4} \square_{2}$ (Krivovichev et al., 2004). In these examples, the $\mathrm{Si}$ or $\mathrm{Ge}$ was replaced by higher valence cations, with charge compensation by oxygen ions that stabilized $A_{10} B_{6} \mathrm{O}_{24} \square_{2}, N=$ 2 polysomes, rather than $A_{15} B_{9} \mathrm{O}_{33} \square_{3}, N=3$ phases. There is a single example where the $3 H$ (or $3 T$ ) polysome is maintained via a coupled $A$ and $B$ site substitution. In an attempt to induce oxygen interstitials in $\mathrm{Pb}_{15} \mathrm{Ge}_{9} \mathrm{O}_{33}$ via replacement of $\mathrm{Pb}^{2+}$ by $\mathrm{Bi}^{3+}$ i.e. $\mathrm{Pb}_{15-x} \mathrm{Bi}_{x} \mathrm{Ge}_{9} \mathrm{O}_{33+x / 2}$, a solid solution limit was found $(x=0.09)$, beyond which apatite- $2 H$ forms. However, a combined bismuth $\left(\mathrm{Bi}^{3+}\right)$ and boron $\left(\mathrm{B}^{3+}\right)$ substitution in $\left(\mathrm{Pb}_{15-x} \mathrm{Bi}_{x} \mathrm{Ge}_{9-x} \mathrm{~B}_{x} \mathrm{O}_{11}\right)$ extended the solubility limit to $x=$ 0.6 (Otto \& Loster, 1993). The synthesis was fortuitous as $\mathrm{B}_{2} \mathrm{O}_{3}$ was introduced to control melt viscosity and promote the growth of large single crystals. The resultant material is pyroelectric and could be used for IR radiation detection.

1.2.3. $N=4$. Nasonite-type polysomes are currently poorly represented, and the compositional ranges and nature of structural variants less well understood. The mineral was first described by Penfield and Warren (1899) and later by Palache (1935) as a rare species found in the Franklin Mine. Subsequently, Aminoff (1916) identified its occurrence at Långban. A Weissenberg X-ray study (Frondel \& Bauer, 1951) recognized the structural relationship between nasonite and pyromorphite $\left[\mathrm{Pb}_{10}\left(\mathrm{PO}_{4}\right)_{6} \mathrm{Cl}_{2}\right]$ and reported the lattice parameters $a=10.06$ and $c=13.24 \AA$, cell contents as $\mathrm{Pb}_{12} \mathrm{Ca}_{8^{-}}$ $\left(\mathrm{Si}_{2} \mathrm{O}_{7}\right)_{6} \mathrm{Cl}_{4}$, and postulated the space group as $P 6_{3} / m$ or $P 6_{3}$. A later single-crystal $X$-ray diffraction study found $P 6_{3} / m$ (Giuseppetti et al., 1971), but high-resolution electron microscopy (HRTEM) of the same sample failed to locate the twofold axis and a deviation from hexagonal symmetry was suspected (Brès et al., 1987). This was ascribed to sampling differences between techniques and the presence of nonhexagonal micro-domains that on average gave the appearance of $P 6_{3} / \mathrm{m}$. In $\$ 3.3$ we report the first preparation and crystal structure refinement of synthetic .. $(\beta \alpha \alpha \beta \beta) \alpha \ldots$ apatite- $4 H$ polysomes.

1.2.4. $N>4$. In addition to nasonite $(N=4)$ and ganomalite $(N=3)$ longer sequence polysomatic members are feasible. For example, $\mathrm{Pb}_{40}\left(\mathrm{Si}_{2} \mathrm{O}_{7}\right)_{6}\left(\mathrm{Si}_{4} \mathrm{O}_{13}\right)_{3} \mathrm{O}_{7}$ was proposed for a metastable lead silicate (Stemmermann, 1992), with reflection indexing yielding $a=17.196$ (1), $b=9.928$ (1), $c=28.744$ (2) A, $\beta=90.36$ (1) ${ }^{\circ}$. Several possible polysomes were suggested but the exact nature of this phase is unresolved. The same study intimated that the true structure of the partially characterized phase $\mathrm{Ca}_{3} \mathrm{Si}_{2} \mathrm{O}_{7} \cdot 1 / 3 \mathrm{CaCl}_{2}$ was actually a nasonite-type $(N=4)$ of composition $\mathrm{Ca}_{20}\left(\mathrm{Si}_{2} \mathrm{O}_{7}\right)_{6} \mathrm{Cl}_{4}$ and the orthorhombic cell $a=$ 3.763 (1), $\quad b=34.70$ (1) and $c=16.946(5) \AA \quad$ assigned (Hermoneit et al., 1981), but subsequently a monoclinic metric $\left(P 2_{1} / a\right)$ with $a=18.665(1), b=14.107$ (1), $c=18.139$ (1) А, $\beta=$ $111.65(1)^{\circ}$ was suggested (Ye et al., 1986; Stemmermann, 1992). In addition, $\mathrm{Sr}$ substitution for $\mathrm{Ca}$ was reported and $\mathrm{Ca}_{12} \mathrm{Sr}_{8}\left(\mathrm{Si}_{2} \mathrm{O}_{7}\right)_{6} \mathrm{Cl}_{4}$ can be indexed with a slightly dilated monoclinic cell. More recently, $\mathrm{Eu}^{2+}$ has been introduced to the $\mathrm{Ca}$ site of $\mathrm{Ca}_{20-x} \mathrm{Eu}_{x}\left(\mathrm{Si}_{2} \mathrm{O}_{7}\right)_{6} \mathrm{Cl}_{4}$ as such phases show promise as phosphors (Ding et al., 2007), but a crystallographic analysis is lacking.
Nassau et al. (1977) confirmed the existence of a metastable ' $\mathrm{Pb}_{5} \mathrm{Ge}_{3} \mathrm{O}_{11}$ ', first identified by Hasegawa et al. (1977) during recrystalization of vitreous ' $\mathrm{Pb}_{5} \mathrm{Ge}_{3} \mathrm{O}_{11}$ ' at $723 \mathrm{~K}$, and assigned the hexagonal lattice parameters $a=10.19$ and $c=19.34 \AA$ (no standard deviations were reported). Heating to $823 \mathrm{~K}$ produces the stable crystalline form of ' $\mathrm{Pb}_{5} \mathrm{Ge}_{3} \mathrm{O}_{11}$ ' with the hexagonal lattice parameters $a=10.251$ and $c=10.658 \AA$. We can identify the stable crystalline phase as $\mathrm{Pb}_{15}\left(\mathrm{Ge}_{2} \mathrm{O}_{7}\right)_{3^{-}}$ $\left(\mathrm{GeO}_{4}\right)_{3} \square_{3}$ or ganomalite-(Pb Ge $\square$ ) $-3 H$ (or $3 T$ ) and predict from the lattice parameters that the metastable phase is an $N=$ 6 polysome. Furthermore, it is suggested from the reported non-ferroelectric properties of the metastable ${ }^{2} \mathrm{~Pb}_{5} \mathrm{Ge}_{3} \mathrm{O}_{11}$ ' that its structure contains a centre of symmetry consistent with the stacking sequence $\ldots \beta(\alpha \alpha \alpha \beta \beta \beta) \alpha \ldots$ apatite- $(\mathrm{Pb} \mathrm{Ge} \square)$ $6 H$ and the crystallochemical formula is $\left[\mathrm{Pb}_{12}\right]\left[\mathrm{Pb}_{18}\right]-$ $\left[\left(\mathrm{Ge}_{3} \mathrm{O}_{10}\right)_{6}\right] \square_{6}$ (Table 1); however, experimental confirmation is required.

\section{Experimental methods}

Several new chemistries of the ganomalite and nasonite structure types were investigated to better understand the structural relationships between these polysomes. To this end, two ganomalite solid solutions were prepared $-\mathrm{Pb}_{15-x} \mathrm{Bi}_{x / 2^{-}}$ $\mathrm{Na}_{x / 2}\left(\mathrm{Ge}_{2} \mathrm{O}_{7}\right)_{3}\left(\mathrm{GeO}_{4}\right)_{3} \square_{3}$ and $\mathrm{Ca}_{6} \mathrm{~Pb}_{9}\left(\mathrm{Si}_{2-y} \mathrm{Ge}_{y} \mathrm{O}_{7}\right)_{3^{-}}$ $\left(\mathrm{Si}_{1-z} \mathrm{Ge}_{z} \mathrm{O}_{4}\right)_{3} \square_{3}$ to explore co-doping across the $A$-site and isovalent $B$-site substitutions. The nasonite phases $\mathrm{Ca}_{8} \mathrm{~Pb}_{12}$ $\left(B_{2} \mathrm{O}_{7}\right)_{6} \mathrm{Cl}_{4}(\mathrm{~B}=\mathrm{Si}$ and $\mathrm{Ge})$ were also synthesized. The primary characterization tool was powder X-ray diffraction, with selected materials examined by neutron diffraction and transmission electron microscopy.

\subsection{Synthesis}

All polysomes were synthesized via conventional solid-state reaction techniques. The reagents $\mathrm{PbO}$ (Fisher, 99\%), $\mathrm{CaCO}_{3}$ (Aldrich, 99.9\%), $\mathrm{Bi}_{2} \mathrm{O}_{3}$ (Aldrich, 99.9\%), $\mathrm{Na}_{2} \mathrm{CO}_{3}$ (Fisher, 99\%), $\mathrm{GeO}_{2}$ (Aldrich, 99.99\%), $\mathrm{SiO}_{2}$ (Alfa, 99.99\%) and $\mathrm{CaCl}_{2}$ (Jebchem, 99\%) were mixed in appropriate stoichiometric quantities according to the reactions shown in (1), (2) and (3). Ganomalite samples were synthesized with $x=0,3$ and 6 [see (1)] and $x=0,2,4.5,7$ and $9(x=y+z)$ [see (2)], while the nasonites were silicate and germanate end-members [see (3)].

$$
\begin{gathered}
(15-x) \mathrm{PbO}+(x / 2) \mathrm{Bi}_{2} \mathrm{O}_{3}+(x / 2) \mathrm{Na}_{2} \mathrm{CO}_{3}+9 \mathrm{GeO}_{2} \rightarrow \\
\mathrm{Pb}_{15-x} \mathrm{Bi}_{x / 2} \mathrm{Na}_{x / 2}\left(\mathrm{Ge}_{2} \mathrm{O}_{7}\right)_{3}\left(\mathrm{GeO}_{4}\right)_{3}+(x / 2) \mathrm{CO}_{2} \\
6 \mathrm{CaO}+9 \mathrm{PbO}+(9-x) \mathrm{SiO}_{2}+x \mathrm{GeO}_{2} \rightarrow \\
\mathrm{Ca}_{6} \mathrm{~Pb}_{9}\left(\mathrm{Si}_{2-y} \mathrm{Ge}_{y} \mathrm{O}_{7}\right)_{3}\left(\mathrm{Si}_{1-z} \mathrm{Ge}_{z} \mathrm{O}_{4}\right)_{3} \\
6 \mathrm{CaO}+12 \mathrm{PbO}+12 B \mathrm{O}_{2}+2 \mathrm{CaCl}_{2} \rightarrow \\
\mathrm{Ca}_{8} \mathrm{~Pb}_{12}\left(B_{2} \mathrm{O}_{7}\right)_{6} \mathrm{Cl}_{4}(B=\mathrm{Si} \text { and } \mathrm{Ge})
\end{gathered}
$$

For (1)-(3) the powders were ground in a ball-mill (20 min at 150 r.p.m.), pressed into pellets and heat treated in air in alumina crucibles from $873-1073 \mathrm{~K}$ for $12 \mathrm{~h}$. The samples were 
Table 3

Experimental details.

For all structures: $Z=1$. Experiments were carried out at $298 \mathrm{~K}$ with neutron radiation. Refinement was with 0 restraints.

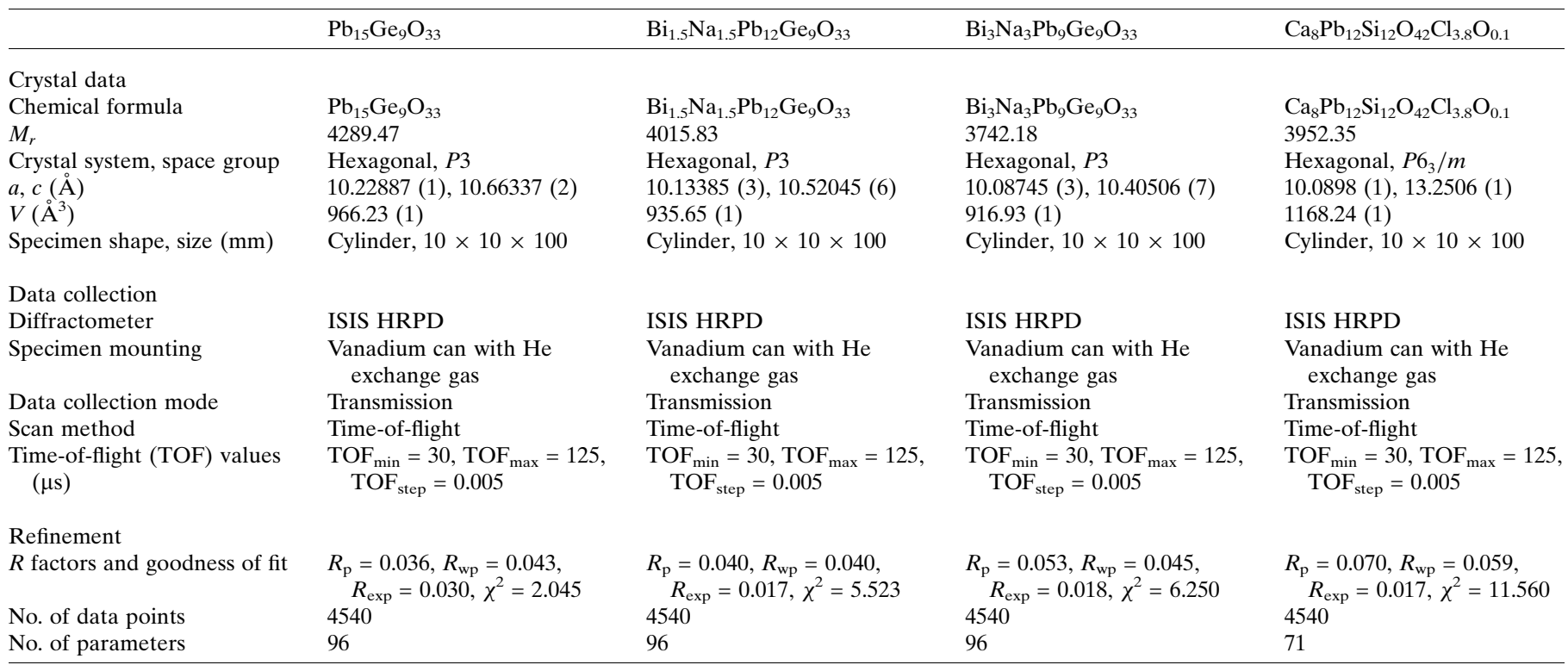

reground, pressed into pellets and re-heated for $48-120 \mathrm{~h}$ until a single-phase or near single-phase product was obtained. In the case of nasonite (3), care was needed to avoid chlorine loss and the pellets were placed in covered alumina crucibles containing excess $\mathrm{NH}_{4} \mathrm{Cl}$ ( $1 \mathrm{~g}$ for $5 \mathrm{~g}$ of sample) to create a chlorine rich atmosphere.

\subsection{Crystallographic characterization}

Sample purity was established and preliminary structural refinements carried out from powder X-ray diffraction (PXRD) patterns collected with a Shimadzu Lab XRD-6000 diffractometer (Bragg-Brentano geometry) equipped with a $\mathrm{Cu} K \alpha \mathrm{X}$-ray tube operated at $40 \mathrm{kV}$ and $40 \mathrm{~mA}$. The crushed powders were mounted in a top-loaded trough and data accumulated from $10-140^{\circ} 2 \theta$ using a step size of $0.02^{\circ}$ with a dwell time of $10 \mathrm{~s}$ per step. Under these conditions the intensity of the strongest peak was 30000-40000 counts. Rietveld refinement of the X-ray data was carried out with TOPAS (Bruker, 2008), using the fundamental parameters approach (Cheary \& Coelho, 1992) and a full axial divergence model (Cheary \& Coelho, 1998). The specimen-dependent parameters refined were the zero error, a user-specified number of coefficients for Chebyshev polynomial fitting of the background, and the 'crystallite size' to model microstructurecontrolled line broadening. Only isotropic atomic displacement parameters (ADPs) were refined. A common ADP was assumed for all $\mathrm{O}$ positions and $\mathrm{Ge}$ and $\mathrm{Si}$ (the $\mathrm{BO}_{4}$ unit), and $\mathrm{Pb} / \mathrm{Bi} / \mathrm{Na} / \mathrm{Ca} / \mathrm{Na}$ occupying the same site. Individual isotropic ADPs were refined for the $\mathrm{Pb} / \mathrm{Bi} / \mathrm{Na} / \mathrm{Ca} / \mathrm{Cl}$ when it was clear that any site was solely occupied by one of these elements. Owing to the almost identical X-ray scattering factors the site preferences of $\mathrm{Pb}$ and $\mathrm{Bi}$ could not be established. To ensure reasonable $\mathrm{Si} / \mathrm{Ge}-\mathrm{O}$ bond lengths within the $\mathrm{Si} / \mathrm{GeO}_{4}$ and $\mathrm{Si} /$ $\mathrm{Ge}_{2} \mathrm{O}_{7}$ units, a soft-constraint was implemented using the 'Parabola_N' penalty function of TOPAS with values for the expected bond lengths consistent with the standard ionic radii of Shannon (1976).

Time-of-flight (TOF) powder neutron diffraction patterns were recorded on the HRPD diffractometer, at ISIS, Rutherford Appleton Laboratory, England, from approximately $2 \mathrm{~cm}^{3}$ of sample loaded into vanadium cans. Data sets from two banks of detectors were used for the refinement; the first was the data from the back-scattering bank (average $2 \theta \simeq 145^{\circ}$ ) and the second was the data from the $90^{\circ}$ detector bank. Structure refinement was performed using the $G S A S$ suite of Rietveld refinement software (Larson \& Von Dreele, 1987). No constraints were imposed on the $\mathrm{Ge} / \mathrm{Si}-\mathrm{O}$ bond lengths using the neutron diffraction data owing to the greater sensitivity of the technique towards oxygen. In addition, individual isotropic ADPs were refined for each oxygen site. Experimental details are given in Table 3.

Transmission electron microscopy (TEM) was conducted on powders deposited on holey-carbon copper grids and loaded in an analytical double tilt holder. Data were obtained at $200 \mathrm{kV}$ using a Jeol JEM-2010 electron microscope (Cs = $0.5 \mathrm{~mm}$ ) equipped with an EDAX EDS X-ray microanalysis system and three field-limiting apertures for selected-area electron diffraction (SAED; 5, 20 and $60 \mathrm{~mm}$ diameter). Highresolution images were collected using an objective aperture $(100 \mu \mathrm{m})$, corresponding to a nominal point-to-point resolution of $\sim 1.7 \AA$. Electron diffraction patterns were calibrated against external standards to derive reliable values for both the electron wavelength and camera length. Lattice parameters were determined repeatedly to check for hysteresis of the electromagnetic lenses leading to errors $< \pm 1 \%$. For 


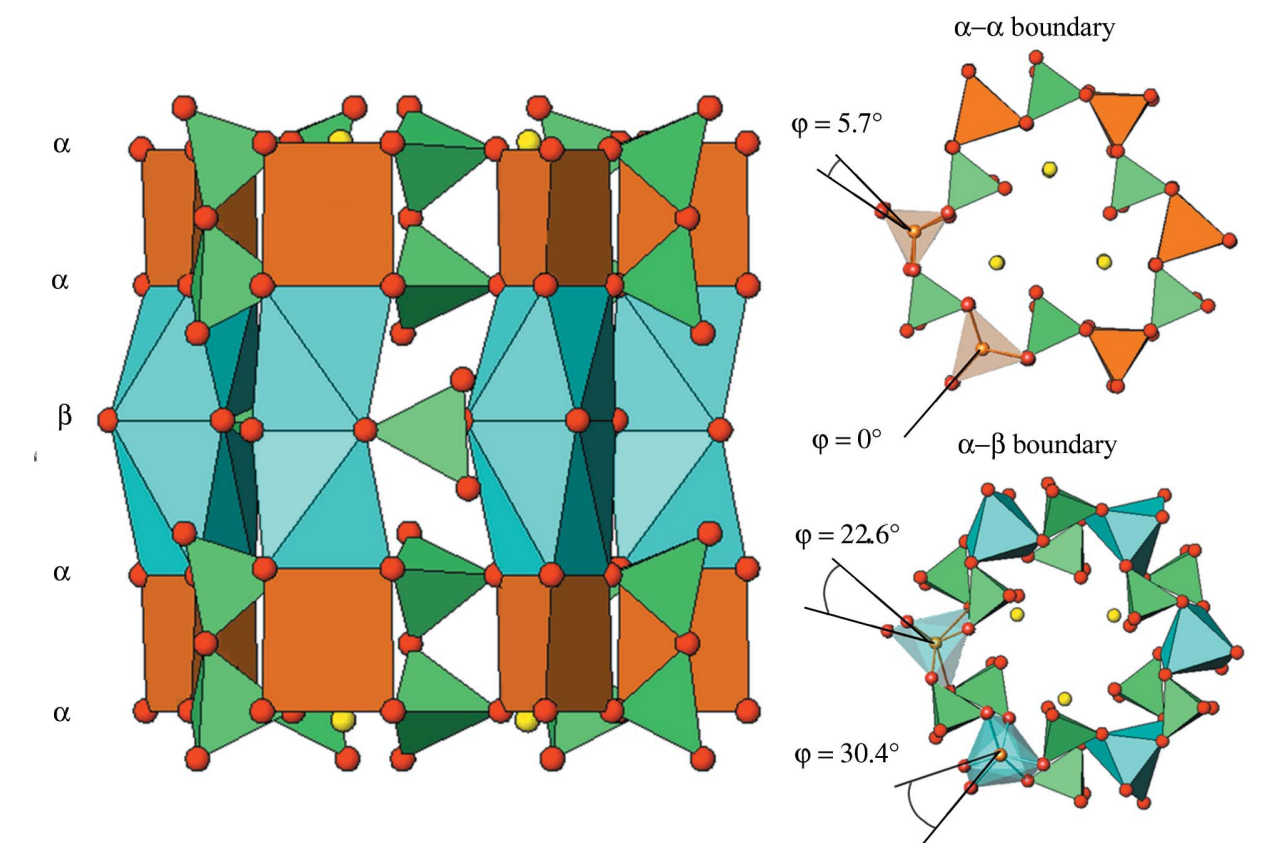

Figure 7

Polyhedral representation of $\quad \ldots \beta(\alpha \alpha \beta) \alpha \ldots \quad$ ganomalite-( $\mathrm{Bi} / \mathrm{Na} / \mathrm{Pb} \mathrm{Ge} \square)-3 T \quad\left[\mathrm{Bi}_{3} \mathrm{Na}_{3}\right]\left[\mathrm{Pb}_{9}\right]-$ $\left[\left(\mathrm{Ge}_{2} \mathrm{O}_{7}\right)_{3}\left(\mathrm{GeO}_{4}\right)_{3}\right] \square_{3}$ including the twist angles $(\varphi)$ for the $\alpha \alpha$ and $\alpha \beta$ boundaries. The metaprisms at the $\alpha-\alpha$ boundary are primarily occupied by smaller $\mathrm{Na}^{+}$and have an acute $\varphi$, while at the $\alpha-\beta$ boundary $\mathrm{Bi}^{+}$ is dominant and $\varphi$ is larger. $\mathrm{Pb}^{2+}$ partitions almost exclusively to the tunnel sites where lone-pair electrons occupy the channel. The substantial distortion of the $\mathrm{BiO}_{6}$ metaprisms may imply that stereochemically active lone-pair electrons are operative.

convergent-beam electron diffraction (CBED), the spot size at the specimen was nominally $10 \mathrm{~nm}$, obtained in the nanoprobe mode.

\section{Results}

\section{1. $\mathrm{Pb}_{15-x} \mathrm{Bi}_{x / 2} \mathrm{Na}_{x / 2}\left(\mathrm{Ge}_{2} \mathrm{O}_{7}\right)_{3}\left(\mathrm{GeO}_{4}\right)_{3}, x=0,3$ and 6: ganomalite-(Pb/Bi/Na Ge $\square)$-3S}

3.1.1. Products. Single-phase materials were produced for $x$ $=0,3$ and 6 , but attempts to prepare lead-free ganomalite $\mathrm{Bi}_{7.5} \mathrm{Na}_{7.5} \mathrm{Ge}_{9} \mathrm{O}_{33}(x=15)$ were unsuccessful and the substitution limit is $x \simeq 6$, i.e. $\mathrm{Pb}_{9} \mathrm{Bi}_{3} \mathrm{Na}_{3} \mathrm{Ge}_{9} \mathrm{O}_{33}$. For $x>6 \mathrm{Bi}_{4} \mathrm{Ge}_{3} \mathrm{O}_{12}$ begins to form together with other poorly crystallized phases, as indicated by broad X-ray diffraction reflections. The optimal reaction temperature was $973 \mathrm{~K}$, although mixtures with high $\mathrm{Bi} / \mathrm{Na}$ content melted congruently.

3.1.2. Structure of $\boldsymbol{x}=\mathbf{0}$. Refinement of $\mathrm{Pb}_{15} \mathrm{Ge}_{9} \mathrm{O}_{33}(x=0)$ neutron data was initially attempted in $P \overline{6}$, however, it was clear from the reliability factors and germanium and oxygen isotropic displacement parameters that $P 3$ yielded a superior fit $\left(P 3: w R_{\mathrm{p}}=0.043, R_{F}=0.036, \chi^{2}=2.001 ; P \overline{6}: w R_{\mathrm{p}}=0.066, R_{F}\right.$ $\left.=0.074, \chi^{2}=4.214\right)$, in agreement with the room-temperature structure of Kay et al. (1975). As with previous studies, the $\mathrm{Pb}^{F}$ position was fixed to define an origin along $z$ and yield reasonable atomic coordinates, bond distances and angles
(Fig. S1a, and Tables S1a and $\mathrm{S} 1 b$ of the supplementary material). ${ }^{2}$ Using the space group $P \overline{6}$ the $\mathrm{Ge} 2, \mathrm{O} 2$ and $\mathrm{O} 3$ sites that are associated with the isolated $\mathrm{GeO}_{4}$ tetrahedra yielded either negative or unreasonably large isotropic displacement parameters and a short $\mathrm{Ge}-\mathrm{O}$ bond length $[1.69(1) \AA]$ and an inferior difference profile fit (see Fig. S1b, and Tables $\mathrm{S} 1 c$ and $\mathrm{S} 1 d)$.

3.1.3. Refinement Strategy for $x=3$ and 6 . For the $\mathrm{Bi}-/ \mathrm{Na}-$ doped polysomes PXRD and neutron data were refined sequentially, as it was anticipated that $\mathrm{Pb}, \mathrm{Na}$ and $\mathrm{Bi}$ would be distributed non-statistically across the $A^{F}$ and $A^{T}$ sites. $\mathrm{Pb}(Z$ $=82)$ and $\operatorname{Bi}(Z=83)$ have very similar X-ray scattering factors and PXRD refinements assumed $\mathrm{Bi}$ as $\mathrm{Pb}$, before examining the distribution of $\mathrm{Na}(Z=23)$ across the $A$ sites, with the $\mathrm{Ge}-$ $\mathrm{O}$ bonds soft-constrained to $\sim 1.7 \AA$ (Shannon, 1976). The refined $\mathrm{Na}$ occupancies were then transferred to the structural model for refinement of the neutron data, where they were fixed and the $\mathrm{Pb}$ and $\mathrm{Bi}$ occupancies refined. This approach will suffer from minor errors as $\mathrm{Pb}$ and $\mathrm{Bi}$ do not have identical form factors, but can be independently checked by comparison against the expected stoichiometry.

The refinements of both the $x=3$ and $6 \mathrm{Bi} / \mathrm{Na}$ polysomes required application of a 'strain' function during XRD analysis, and an $L_{33}$ parameter to the peak-shape function for neutron data. This indicates $c$-axial strain, presumably due to distortions caused by different ionic sizes and a preference for certain sites or module stacking disorder.

The PXRD Rietveld refinements slightly favoured $P 3$ over $P \overline{6}$, as indicated by the reliability factors, and the sodium occupancies gave values close to the nominal compositions. Neutron refinements were also attempted using both space groups, which on the basis of derived occupancies and overall stability (refinements in $P \overline{6}$ tended to result in $\mathrm{Pb}$ and $\mathrm{Bi}$ occupancies with non-physical values) confirmed $P 3$ as most probable. The lower symmetry is possibly favoured as it provides a greater number of discrete cation acceptor sites to accommodate the site preferences of $\mathrm{Pb} / \mathrm{Bi} / \mathrm{Na}$.

In both $\mathrm{Pb}_{12} \mathrm{Bi}_{1.5} \mathrm{Na}_{1.5} \mathrm{Ge}_{9} \mathrm{O}_{33}(x=3)$ and $\mathrm{Pb}_{9} \mathrm{Bi}_{3} \mathrm{Na}_{3} \mathrm{Ge}_{9} \mathrm{O}_{33}$ $(x=6) \mathrm{Na}$ ions strongly partition to the framework. $A 5^{F}$ and

\footnotetext{
${ }^{2}$ Supplementary data for this paper are available from the IUCr electronic archives (Reference: BK5091). Services for accessing these data are described at the back of the journal.
} 


\section{Table 4}

(a) Pawley fit residuals $\left(R_{\mathrm{wp}}\right)$ for different number of ganomalite-3H(T) phases contained in samples of $\mathrm{Ca}_{6} \mathrm{~Pb}_{9} \mathrm{Si}_{9-x} \mathrm{Ge}_{x} \mathrm{O}_{33}$ with $x=0,2,4.5,7$ and 9; $(b)$ refined lattice parameters and volumes determined from the Pawley fits.

The phase with intermediate lattice parameters or the 'equilibrated' phase is designated as ' $\mathrm{B}$ ' in all cases.

\begin{tabular}{lllc}
\hline$(a)$ & & & \\
$x$ & 1 phase & 2 phase & 3 phase \\
\hline 0 & 12.24 & 6.82 & 5.36 \\
2 & 11.59 & 6.13 & 4.88 \\
4.5 & 16.11 & 8.76 & 6.43 \\
7 & 14.86 & 9.53 & 7.70 \\
9 & 16.90 & 13.22 & 10.31 \\
\hline
\end{tabular}

(b)

\begin{tabular}{|c|c|c|c|c|c|c|}
\hline \multirow[b]{2}{*}{ Phase } & \multicolumn{3}{|l|}{$x=0$} & \multicolumn{3}{|l|}{$x=2$} \\
\hline & $\overline{0 A}$ & OB & $0 \mathrm{C}$ & $2 \mathrm{~A}$ & $2 \mathrm{~B}$ & $2 \mathrm{C}$ \\
\hline$a(\AA)$ & $9.8783(1)$ & $9.8820(1)$ & $9.8870(2)$ & 9.9038 (2) & 9.9181 (2) & $9.9480(3)$ \\
\hline$c(\AA)$ & $10.1891(2)$ & $10.2163(2)$ & $10.2406(3)$ & $10.2232(3)$ & $10.2399(3)$ & $10.2653(4)$ \\
\hline $\operatorname{Vol}\left(\AA^{3}\right)$ & $861.05(3)$ & $864.00(3)$ & $866.93(4)$ & $868.40(4)$ & $872.34(4)$ & $879.79(6)$ \\
\hline Crystal size (nm) & $280(15)$ & $350(40)$ & $180(8)$ & $265(20)$ & $193(15)$ & $68(1)$ \\
\hline
\end{tabular}

\begin{tabular}{|c|c|c|c|c|c|c|}
\hline \multirow[b]{2}{*}{ Phase } & \multicolumn{3}{|l|}{$x=4.5$} & \multicolumn{3}{|l|}{$x=7$} \\
\hline & $4.5 \mathrm{~A}$ & $4.5 \mathrm{~B}$ & $4.5 \mathrm{C}$ & $7 \mathrm{~A}$ & $7 \mathrm{~B}$ & $7 \mathrm{C}$ \\
\hline$a(\AA)$ & 9.9447 (3) & 9.9998 (2) & 10.0517 & $10.0198(7)$ & $10.0777(2)$ & $10.0922(2)$ \\
\hline$c(\AA)$ & $10.2651(5)$ & $10.3054(3)$ & $10.3494(5)$ & $10.3351(10)$ & $10.3649(2)$ & $10.4114(3)$ \\
\hline $\operatorname{Vol}\left(\AA^{3}\right)$ & $879.17(7)$ & $892.44(5)$ & $905.58(7)$ & $898.60(15)$ & $911.64(4)$ & $918.35(5)$ \\
\hline \multirow[t]{2}{*}{ Crystal size $(\mathrm{nm})$} & $93(3)$ & $100(3)$ & $92(3)$ & $46(1)$ & $132(5)$ & $188(10)$ \\
\hline & & $x=9$ & & & & \\
\hline Phase & & $9 \mathrm{~A}$ & & $9 \mathrm{~B}$ & & $9 \mathrm{C}$ \\
\hline$a(\AA)$ & & 10.1061 & & $10.0991(2)$ & & $10.1108(2)$ \\
\hline$c(\AA)$ & & $10.3817(2)$ & & $10.4234(3)$ & & $10.4710(3)$ \\
\hline $\operatorname{Vol}\left(\AA^{3}\right)$ & & $918.26(4)$ & & 920.69 (4) & & $927.02(5)$ \\
\hline Crystal size (nm) & & $314(20)$ & & $200(11)$ & & $179(7)$ \\
\hline
\end{tabular}

both $\mathrm{Bi}^{3+}(1.17 \AA)$ and $\left.\mathrm{Na}^{+}(1.18 \AA)\right]-$ with a distribution different from apatite$2 \mathrm{H}$, where the $\mathrm{Bi}^{3+}$ was found from $\mathrm{X}$ ray work to be located in the $A^{T}$ sites, e.g. $\mathrm{Pb}_{7.4} \mathrm{Bi}_{0.3} \mathrm{Na}_{2.3}\left(\mathrm{PO}_{4}\right)_{6} \square_{2}$ (Hamdi et al., 2007) and $\mathrm{Pb}_{4.6} \mathrm{Bi}_{0.4} \mathrm{Ca}_{2.6^{-}}$ $\mathrm{Na}_{2.4}\left(\mathrm{PO}_{4}\right)_{6} \square_{2}$ (Hamdi et al., 2004). For $\mathrm{Pb}_{12} \mathrm{Bi}_{1.5} \mathrm{Na}_{1.5} \mathrm{Ge}_{9} \mathrm{O}_{33}$ bismuth entered $A 5^{F}$ and $A 6^{F}$ preferentially with lead favouring $A 1^{F}$ and $A 2^{F}$. The site occupancies of $A 3^{F}$ and $A 4^{F}$ were ambiguous with either all the $\mathrm{Bi}$ at $A 3^{F}$ with all the $\mathrm{Pb}$ located at $A 4^{F}$, or vice versa, and no differentiation by the reliability indices. Therefore, $\mathrm{Pb} / \mathrm{Bi}$ were distributed evenly and fixed. The final refined $\mathrm{Bi}$ content was higher than anticipated (1.81 compared to the ideal value of 1.50). It is noted that the presence of $A^{F} / A^{T}$ cation vacancies could not be probed as the refinement strategy required full occupancy of all sites. An alternative explanation for $\mathrm{Na}^{+}$and $\mathrm{Bi}^{3+}$ occupying the framework is the need to locally conserve charge.

3.1.5. Structure of $x=6$. The investigation of $\mathrm{Pb}_{9} \mathrm{Bi}_{3} \mathrm{Na}_{3} \mathrm{Ge}_{9} \mathrm{O}_{33}(x=6)$ was straightforward; once the $\mathrm{Na}$ occupancies were determined by PXRD the remainder of the framework sites were filled with $\mathrm{Bi}$; $\mathrm{Na}$ entered the $A^{T}$ sites $(\sim 0.36 \mathrm{Na}$ per unit formula) to a minor extent with the majority located in the framework sites. $\mathrm{Bi}^{3+}$ was introduced to the tunnel sites but the refinement was unconvincing, with ready convergence achieved with $\mathrm{Bi}^{3+}$ on $A^{F}$ positions to

$A 6^{F}$ were the most favoured cation-acceptor sites for sodium (from the $\mathrm{Pb}_{15} \mathrm{Ge}_{9} \mathrm{O}_{33}$ parent), $A 2^{F}$ the second most favoured site, with the $A 1^{F} / 3^{F} / 4^{F}$ positions showing similar affinity for $\mathrm{Na}$ occupancy; the preferred sites $\left(A 5^{F}\right.$ and $\left.A 6^{F}\right)$ are located next to the $(\alpha \alpha)$ double tetrahedral units. For $x=3$ sodium was excluded from the tunnel, with only very partial inclusion in the $x=6$ sample. This is consistent with the requirement for stereochemically active $\mathrm{Pb}^{2+}$ lone-pair electrons to stabilize the channels, and may explain why the solid-solution upper limit is $x \simeq 6$. The possible occurrence of oxygen within the channels was tested by placing low occupancy ions at several trial positions; however, this yielded poor reliability factors and non-convergence, indicating that the tunnel is indeed empty.

3.1.4. Structure of $x=3 . \mathrm{Bi}^{3+}$ was tenanted in the $A^{F}$ sites, rather than the $A^{T}$ positions, even though this ion also possesses stereochemically active lone-pair electrons that could in principle mimic $\mathrm{Pb}^{2+}$ for stabilizing the empty channels. This suggests that ionic size ultimately determines their location within the $3 T$ polysome $-\left[\mathrm{Pb}^{2+}\right.$ is larger $(1.29 \AA)$ than yield a total of $3.32 \mathrm{Bi}^{3+}$ per unit formula, compared with the ideal value of 3. An unrealistically high ADP for $A 1^{F}\left(U_{\text {iso }}=\right.$ $\left.0.058 \AA^{3}\right)$ was improved $\left(U_{\text {iso }}=0.025 \AA^{3}\right)$ by introducing $0.32 \mathrm{~Pb}$ at this site in an attempt to improve the overall stoichiometry and charge balance. The absolute values for the refined occupancies should be treated with some caution owing to the nature of the refinement; they do however offer a good indication to the preferred location of the different chemical species. Nevertheless, all of the ADPs were high, which may arise from module stacking disorder. It is noted that the $A^{F}-\mathrm{O}$ bond lengths of the $A 6^{F}$ site (occupied by Na) are quite distorted compared with the other refinements, perhaps owing to the influence of nearby $\mathrm{Bi}^{3+}$ lone pair electrons.

The refined atomic positions, site occupancies and selected bond lengths are shown in Figs. S2 and S3, and Tables S2 $(a)$ (c) and $\mathrm{S} 3(a)-(c)$. The structure drawing of $\mathrm{Pb}_{9} \mathrm{Bi}_{3} \mathrm{Na}_{3} \mathrm{Ge}_{9} \mathrm{O}_{33}$ emphasizes the clear preference of $\mathrm{Bi}$ and $\mathrm{Na}$ for the framework (Fig. 7) and the general formula of this series can be written as $\left[\mathrm{Bi}_{x / 2} \mathrm{Na}_{x / 2}\right]\left[\mathrm{Pb}_{15-x}\right]\left(\mathrm{Ge}_{2} \mathrm{O}_{7}\right)_{3}\left(\mathrm{GeO}_{4}\right)_{3} \square_{3}$. 
3.2. $\mathrm{Ca}_{6} \mathrm{~Pb}_{9}\left(\mathrm{Si}_{2-x} \mathrm{Ge}_{x} \mathrm{O}_{7}\right)_{3}\left(\mathrm{Si}_{1-x} \mathrm{Ge}_{x} \mathrm{O}_{4}\right)_{3} \square_{3}$ : ganomalite(Pb Si/Ge $\square)-3 S$

3.2.1. Products. Powder $X$-ray diffraction confirmed ganomalite $-(\mathrm{Pb} \mathrm{Si} / \mathrm{Ge} \square)-3 S$ could be synthesized across the entire series, with minor $\mathrm{Pb}_{3}(\mathrm{Si}, \mathrm{Ge})_{3} \mathrm{O}_{7}$ and/or $\mathrm{Ca}(\mathrm{Si}, \mathrm{Ge}) \mathrm{O}_{3}$ impurities removed by repeated grinding and heat treatments. The optimal reaction condition was $1073 \mathrm{~K}$ for $36 \mathrm{~h}$, divided into three sintering stages $(12 \mathrm{~h})$ with intermediate grinding. Higher temperature or prolonged heating resulted in partial product decomposition presumably owing to lead volatilization.

3.2.2. Structural characterization. Close inspection of the sharp XRD diffraction peaks revealed anisotropy, particularly the $00 l$ reflections, suggestive of phase segregation. Similar observations in $\left(\mathrm{Ca}_{10-x} \mathrm{~Pb}_{x}\right)\left(\mathrm{VO}_{4}\right)_{6} \mathrm{~F}_{2}$ apatites were shown to be due to the non-equilibrated partitioning of calcium and lead over $A^{F}(4 f)$ and $A^{T}(6 h)$ sites $\left(P 6_{3} / m\right)$, which favoured $\mathrm{Pb}^{2+}$ preferentially entering the larger $A^{T}$ site (Dong \& White, 2004a); prolonged heating ( 4 weeks at $1073 \mathrm{~K}$ ) was required to obtain the equilibrium structures (Dong \& White, 2004b).

Pawley fits showed all the materials were three-phase assemblages (see Table 4). Single-phase refinements were attempted with the inclusion of a function to model anisotropic peak broadening; however, this offered little improve-

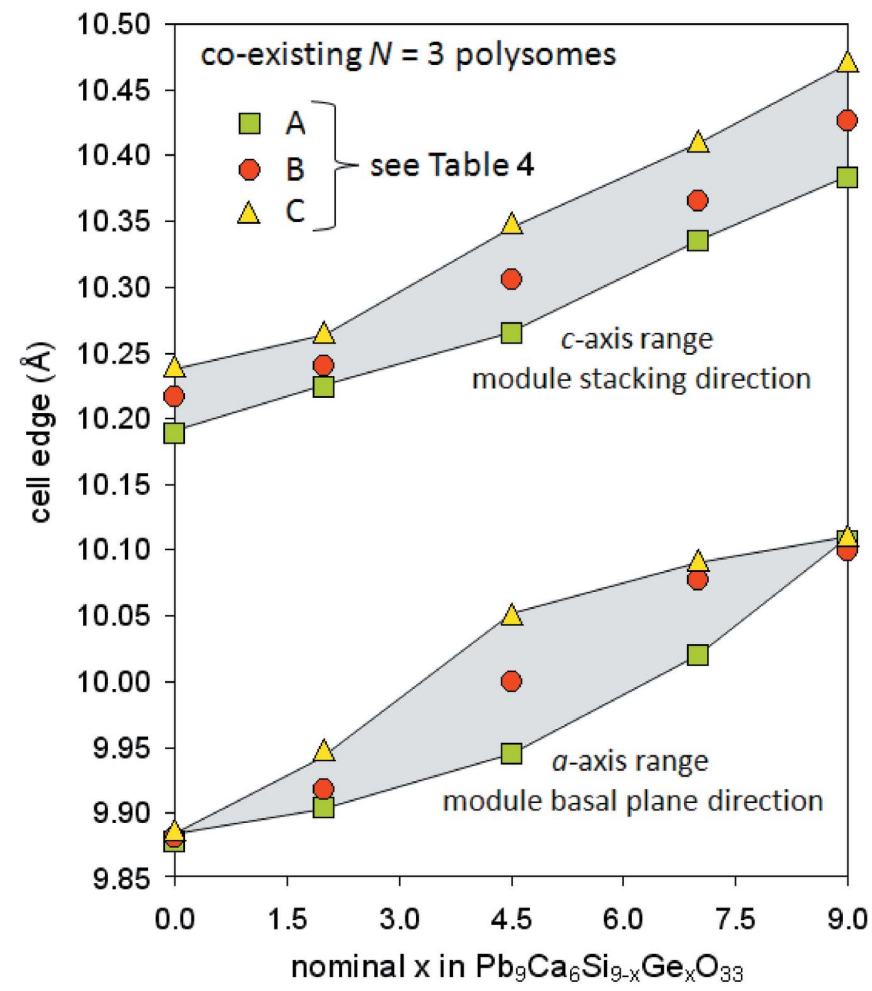

Figure 8

Refined lattice parameters for the three phase assemblages in $\mathrm{Ca}_{6} \mathrm{~Pb}_{9} \mathrm{Si}_{9-x} \mathrm{Ge}_{x} \mathrm{O}_{33}$ polysomes. Disequilbrium is reminiscent of that observed previously in $(\mathrm{Ca}, \mathrm{Pb})_{10}\left(\mathrm{VO}_{4}\right)_{6} \mathrm{~F}_{2}$ apatites where several weeks high-temperature annealing were required to obtain a stable phase assemblage (Dong \& White, 2004a,b). Over the whole compositional range the greater span of the $c$ axis, compared with the basal plane, may reflect module, chemical or stacking disorder. ment in the residuals indicating that the samples contained more than one phase.

For preparations of nominal compositions $\mathrm{Ca}_{6} \mathrm{~Pb}_{9}$ $\left(\mathrm{Si}_{2} \mathrm{O}_{7}\right)_{3}\left(\mathrm{SiO}_{4}\right)_{3} \square_{3}$ and $\mathrm{Ca}_{6} \mathrm{~Pb}_{9}\left(\mathrm{Ge}_{2} \mathrm{O}_{7}\right)_{3}\left(\mathrm{GeO}_{4}\right)_{3} \square_{3}$ the polysomes had similar a cell edges but the $c$ parameters showed slightly larger variations. The compounds having the largest and smallest volumes are presumably rich in $\mathrm{Pb}^{2+}$ and $\mathrm{Ca}^{2+}$, while the phase with the intermediate $c$ parameter was nearer equilibration. Preparations containing mixed Si/Ge occupancies $(x=2,4.5$ and 7$)$ showed a greater variation in their lattice parameters, especially along the [001] module stacking direction, indicating a more complex cation distribution and a delay in ordering (see Fig. 8 and Table 4). As Si (IR $=0.40 \AA$ ) is displaced by Ge (IR $=0.53 \AA$ ) unit-cell dilation is expected (Fig. 8), and for the polysomes closest to equilibration ( $B$ phase) the expansion was essentially linear, in agreement with Vegard's law. Discontinuities of equivalent plots for the nonequilibrated $A$ and $C$ phases indicate a more complex partitioning behaviour.

3.2.3. Convergent-beam electron diffraction (CBED) of $\left[\mathrm{Ca}_{6}\right]\left[\mathrm{Pb}_{9}\right]\left[\left(\mathrm{Si}_{2} \mathrm{O}_{7}\right)_{3}\left(\mathrm{SiO}_{4}\right)_{3} \square_{3}\right.$. Most ganomalite samples were electron-beam sensitive and decomposed rapidly. However, for a single composition it was possible to collect CBED patterns for ganomalite- $\mathrm{Ca}_{6} \mathrm{~Pb}_{9}\left(\mathrm{Si}_{2} \mathrm{O}_{7}\right)_{3}\left(\mathrm{SiO}_{4}\right)_{3}$ and unam-

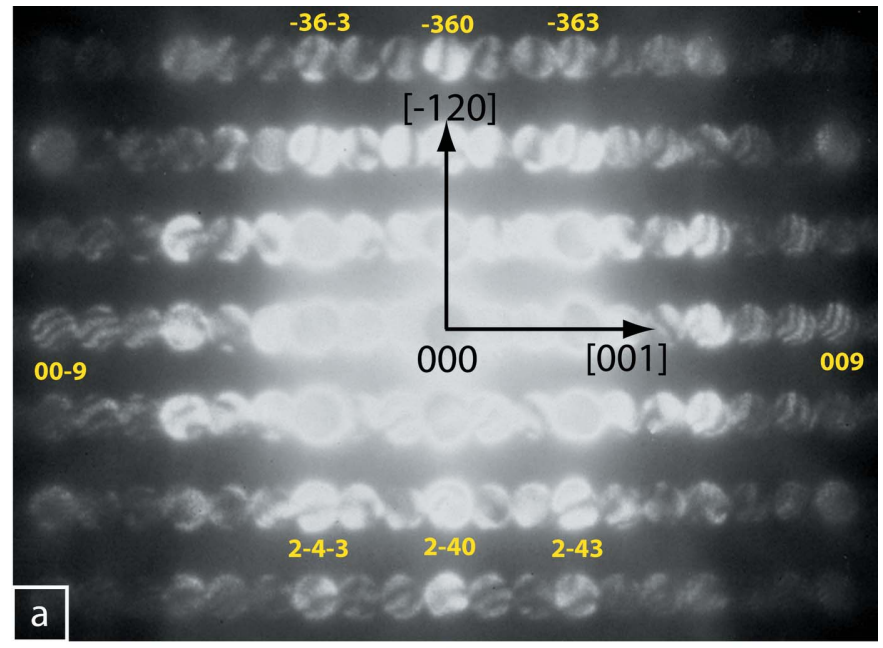

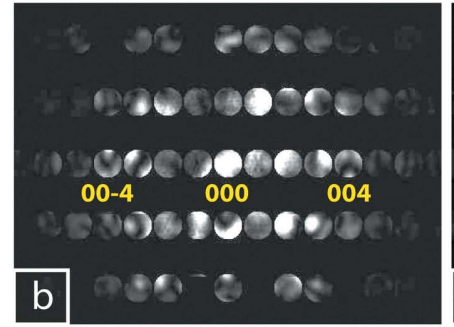

$P 3-[210] p 1$

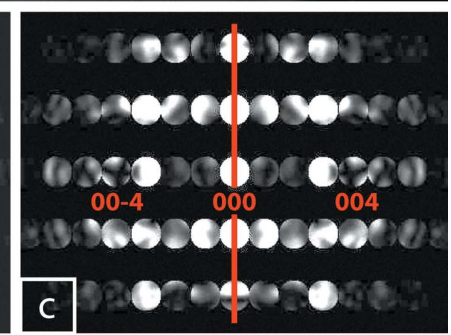

$P \overline{6}-[210] p 11 m$
Figure 9

(a) Convergent-beam electron diffraction (CBED) pattern of $\left[\mathrm{Ca}_{6}\right]\left[\mathrm{Pb}_{9}\right]\left[\left(\mathrm{Si}_{2} \mathrm{O}_{7}\right)_{3}\left(\mathrm{SiO}_{4}\right)_{3}\right] \square_{3}$ aligned along [210]. The absence of a mirror plane parallel to [120] is clear from the non-equivalence of the indexed reflections and is consistent with trigonal symmetry. $(b)$ and $(c)$ are simulated CBED for $P 3$ and $P \overline{6}$. In hexagonal symmetry the mirror plane (vertical line) is evident as, for example, in the mirror relationship of 004 and $00 \overline{4}$ reflections. 
biguously distinguish between $P 3$ and $P \overline{6}$ by examining special projections along [210] that will conform to plane symmetry $p 1$ and $p 11 m$, respectively. Several [210] CBED patterns were collected under different conditions to verify the presence of a mirror plane parallel to [1 120$]$ as anticipated in $P \overline{6}$ symmetry. In addition to experimental zero-order Laue zone (ZOLZ) CBED, Bloch wave simulations with $1.2 \mathrm{mrad}$ half-convergent illumination and $150 \mathrm{~nm}$ thickness for $P 3$ and $P \overline{6}$ were calculated using the JEMS simulation program (Stadelmann, 2003). The clear absence of a mirror plane (Fig. 9) confirms this ganomalite polysome belongs to $P 3$. This is particularly evident when comparing high-angle reflections (far from the direct beam) where over-exposure effects are less pervasive (Fig. 9a) and dynamical contrast distributions are not related by mirroring (Figs. $9 b$ and $c$ ).

3.2.4. Disequilibrium, phase separation and functionality. The fact that for each sample three distinct phases were found in approximately equal quantities, but containing different cation distributions and crystal sizes may explain the anomalies found in previous ganomalite- $3 S$ structural determinations, i.e. space-group assignment and atomic displacement parameters. Furthermore, natural ganomalite may also contain micro-domains with similar hexagonal matrices, which would contribute to ambiguous structural studies. This may not be an unusual feature in apatites, as, for example, a natural crystal of a Brazilian gem-grade apatite was found to contain microdomains of $\mathrm{F}$ and $\mathrm{Cl}$ enriched apatites each with similar $c$

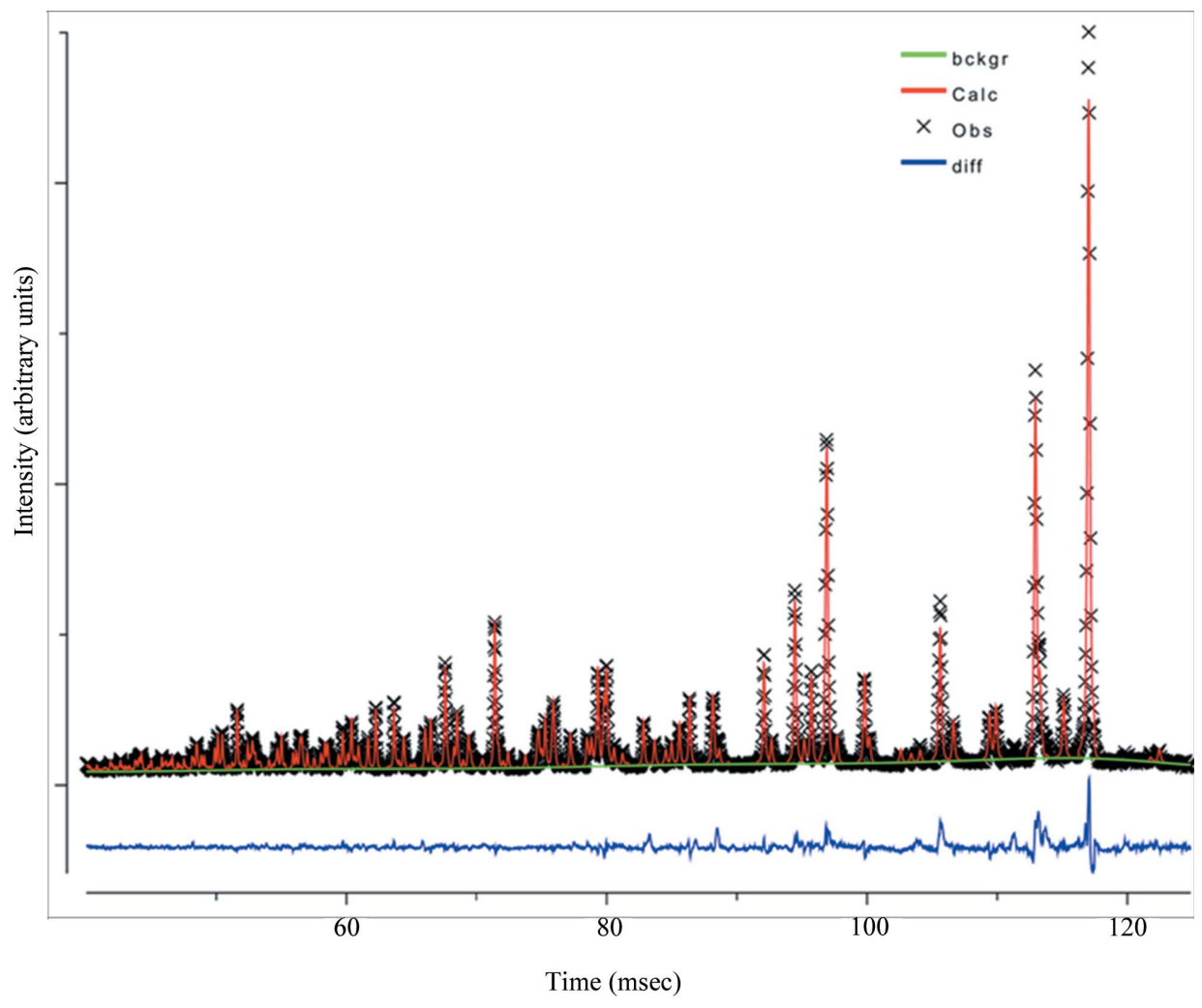

Figure 10

Rietveld refinement of the neutron time-of flight (TOF) data for $\mathrm{Ca}_{8} \mathrm{~Pb}_{12}\left(\mathrm{Si}_{2} \mathrm{O}_{7}\right)_{6} \mathrm{Cl}_{4}$. parameters but with differing a lattice parameters (Ferraris et al., 2005).

Multi-phase ganomalite samples might also have been encountered in studies of their ferroelectric properties where diffuse transitional temperatures were reported (Goswami et al., 1997, 2001; Goswami, Mahapatra et al., 1998; Choudhary \& Misra, 1998; Misra et al., 1999). Although indexing the XRD patterns indicated single-phase products, the materials could be similar to those obtained here and contain mixtures with comparable lattice parameters, but differing cation distributions. In contrast, a report on the ferroelectric properties of a single-crystal sample of $\mathrm{Pb}_{15} \mathrm{Ge}_{9} \mathrm{O}_{33}$ and no phase segregation, showed a sharp transition temperature. Interestingly, measurement of the transition temperature of a 'single crystal' of $\mathrm{Pb}_{15} \mathrm{Ge}_{6} \mathrm{Si}_{3} \mathrm{O}_{33}$ was broad, which may be indicative of the existence of micro-domains (Iwasaki, Miyazawa et al., 1972), as in apatite gems (Ferraris et al., 2005).

\section{3. $\mathrm{Ca}_{8} \mathrm{~Pb}_{12}\left(B_{2} \mathrm{O}_{7}\right)_{6} \mathrm{Cl}_{4}(B=\mathrm{Si}$ and $\mathrm{Ge})$ : nasonite-( $\mathrm{Pb} \mathrm{Si} / \mathrm{Ge}$ Cl) $-4 \mathrm{H}$}

3.3.1. Products. Nasonite- $(\mathrm{Pb} \mathrm{Si} \mathrm{Cl})-4 H$ was prepared as a single phase, while the synthesis of the germanate analogue was partially successful, with PXRD revealing several unidentified reflections. The optimal synthesis temperature for the silicate polysome was $873 \mathrm{~K}$, with $973 \mathrm{~K}$ required to form the germanate nasonite. The higher-synthesis temperature resulted in excessive $\mathrm{Cl}$ loss whereby nasonite converts to ganomalite. In addition, the impurity phase $\mathrm{Pb}_{2}(\mathrm{Si}, \mathrm{Ge})_{3} \mathrm{O}_{9}$ (margarosanite) was found in the reaction products. Due to its multiphase nature only lattice parameters of $\mathrm{Ge}$ nasonite are reported.

3.3.2. Structure of $\mathrm{Ca}_{8} \mathrm{~Pb}_{12^{-}}$ $\left(\mathbf{S i}_{2} \mathbf{O}_{7}\right)_{6} \mathbf{C l}_{4}$. Neutron diffraction refinements for $\mathrm{Ca}_{8} \mathrm{~Pb}_{12}$ $\left(\mathrm{Si}_{2} \mathrm{O}_{7}\right)_{6} \mathrm{Cl}_{4}$ were attempted in $P 6_{3} / m$ and $P 6_{3}$, with the former being the preferred model (Figs. 10 and S4). The refinement proceeded directly to give lattice parameters and atomic positions close to those previously reported, however, the chlorine sites yielded an occupancy slightly less than 1 . In addition, moving the $\mathrm{Cl}$ ions off the special positions along the channel to partially occupied split sites lowered their ADPs to more realistic values, although still quite high. A difference-Fourier map also indicated a small excess of nuclear density between the $\mathrm{Cl}$ atoms close to $(0,0,1 / 8)$. This site 
is commonly occupied by oxygen in apatite- $2 S$, and therefore a comparable site was introduced between the chlorine ions. Oxygen ions were initially placed at $(0,0,1 / 8)$, however, their stability was improved by site splitting, suggesting channel disorder as commonly encountered in the $N=2$ polysomes (White \& ZhiLi, 2003). The occupancy of the tunnel O5 oxygen site was initially refined without constraint; however, a restriction of chemistry $\left(4-x \mathrm{Cl}^{-}+x / 2 \mathrm{O}^{2-}\right.$ to give an overall charge of -4 ) was ultimately applied to ensure overall charge neutrality. It is possible that the $\mathrm{O} 5$ is $\mathrm{OH}$, but this could not be confirmed owing to the low occupancy.

A structural model was developed that gave a good fit to the data (Table S4a), however, the ADPs, although tolerable, were slightly high, particularly for $\mathrm{Pb}$. This may be indicative of polysynthetic module rotation twinning (as confirmed subsequently by HRTEM below). Selected bond lengths and angles
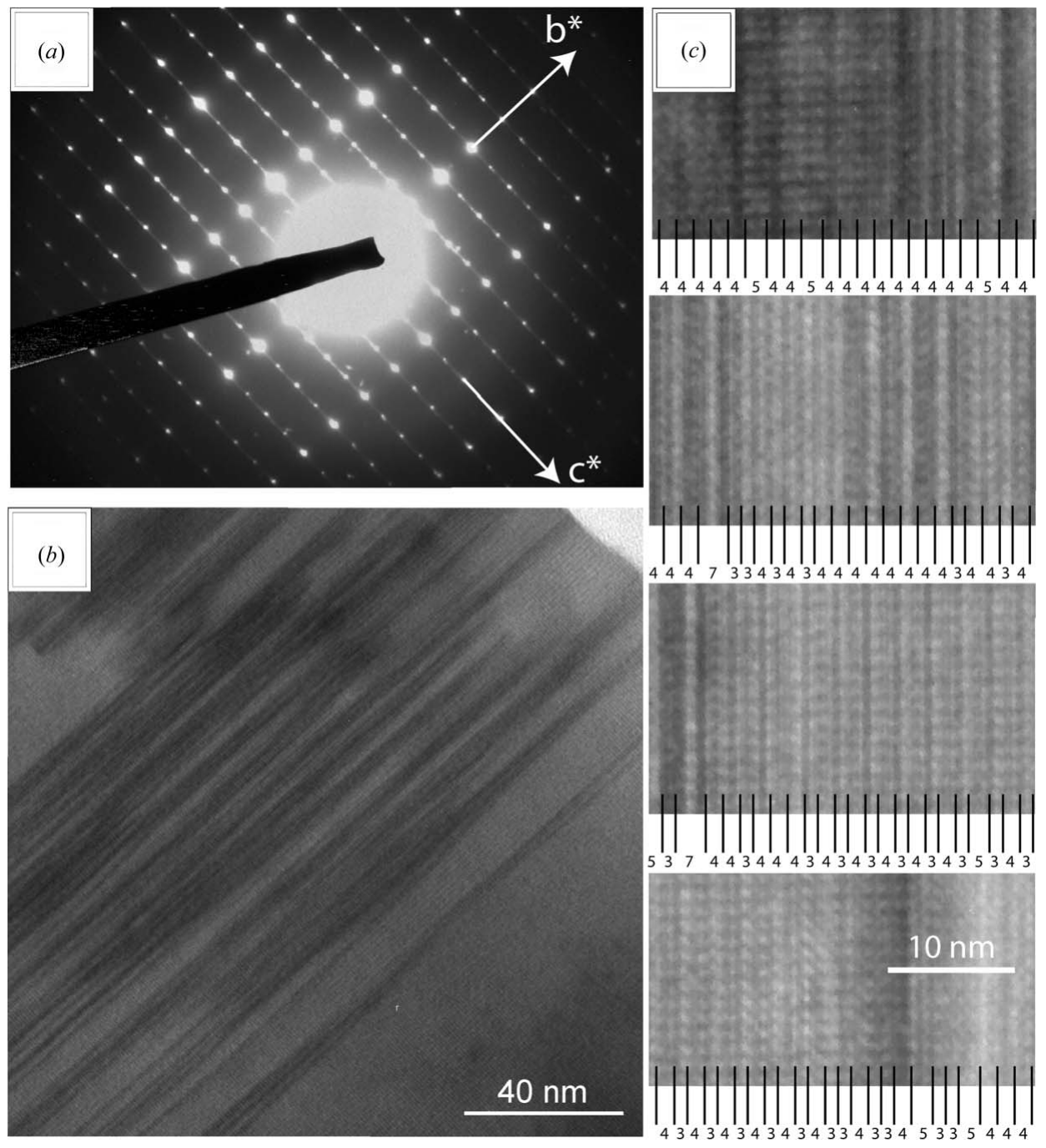

\section{Figure 11}

Disordered module intergrowth (polysynthetic twinning) in nominal $N=4 \mathrm{Ca}_{8} \mathrm{~Pb}_{12}\left(\mathrm{Si}_{2} \mathrm{O}_{7}\right)_{6} \mathrm{Cl}_{4}$ was observed in $\simeq 5 \%$ of crystal fragments. (a) [100]* SAEDs from areas containing $\alpha, \beta$ module disorder are characterized by the presence of dynamical forbidden $(00 l)$ reflections with $l \neq 2 n$ and pronounced streaking. (b) Low magnification images show modulated contrast indicative of disorder. (c) HRTEM can be interpreted as mainly $N=4$ and $N=3$ polysomes with intercalation of $N=5$ or 7 recognized less frequently.
(Table $\mathrm{S} 4 b$ ) are also in good agreement with the single-crystal mineral (Giuseppetti et al., 1971); however, in this work the structure was refined with substantially higher accuracy.

3.3.3. TEM analysis. Microscopy of $N=4 \mathrm{Ca}_{8} \mathrm{~Pb}_{12}$ $\left(\mathrm{Si}_{2} \mathrm{O}_{7}\right)_{6} \mathrm{Cl}_{4}$ nasonite shows disordered stacking sequences of $\alpha$ and $\beta$ layers along [001] in an estimated $5 \mathrm{vol} \%$ of crystals. [100] SAED patterns from an area containing disorder (Fig. $11 a)$ contains, in addition to dynamically forbidden $(00 l)$ reflections with $l \neq 2 n$, pronounced [001]* streaking. Lower magnification images possess evident bands of dark and light contrast (Fig. 11b) arising from extensive defect intergrowths. In a detailed analysis of a HRTEM segment $N=4$ and $N=3$ nit cells often regularly alternate along $\mathbf{c}^{*}$ in a ...3(34)4 ... sequence. Intercalation of $N=5$ or 7 polysomes is also recognisable (Fig. 11c) but rare, suggesting $\mathrm{Si}_{n} \mathrm{O}_{3 n+1}, n \geq 4$ are stereochemically unfavourable.

3.3.4. Structure of $\mathrm{Ca}_{8} \mathrm{~Pb}_{12}\left(\mathrm{Ge}_{2} \mathrm{O}_{7}\right)_{6} \mathrm{Cl}_{4}$. The lattice parameters for $\mathrm{Ca}_{8} \mathrm{~Pb}_{12}\left(\mathrm{Ge}_{2} \mathrm{O}_{7}\right)_{6} \mathrm{Cl}_{4} \quad[a=$ $10.3144(3)$ and $c=$ 13.5342 (4) $\AA$ ] were obtained from a Pawley fit in $P 6_{3} / \mathrm{m}$. Owing to the multiphase nature of this sample no structural refinement was attempted, nor is further discussion presented here. It is anticipated that a single-phase product of the germanium nasonite could be prepared using a hermetically sealed system to prevent chlorine loss.

\section{Discussion}

\subsection{Expanded phase space for the apatite family}

The initial crystal-structure determination of hexagonal $\left(\mathrm{P}_{3} / \mathrm{m}\right) \quad$ fluorapatite(Ca P F)-2H almost 80 years ago (Naray-Szabo, 1930) was followed by several decades of solid-state investigations from which around 100 chemical analogues arose (Wyckoff, 1965), generally described within the constraint of the prototype symmetry. In parallel with the examination of synthetics, a range of minerals including the aesthetic mimetite-( $\mathrm{Pb} \mathrm{As} \mathrm{Cl})$ $2 H$ (Calos \& Kennard, 1990) 
and vanadinite- $(\mathrm{Pb} \mathrm{V} \mathrm{Cl})-2 H$ (Dai \& Hughes, 1989) varieties were reported. The seminal study of Elliott et al. (1973) first validated the monoclinic $P 2_{1} / b \quad 2 M$ dimorph of hydroxyapatite and served as a prelude to the structural re-determination of many apatites and the conspicuous expansion of their subtle crystallochemical complexities (Pramana et al., 2008). It is now recognized that the apatite family exploits seven adaptive mechanisms including:

(i) cation ordering in chemically complex members with minimal $A_{4}^{F}\left(B_{0} \mathrm{O}_{4}\right)_{6}$ framework distortion (metaprism twist angle $\varphi<25^{\circ}$ ) that is accommodated in the $P 6_{3}, P \overline{6}$ and $P \overline{3}$ maximal isomorphic subgroups of $P 6_{3} / \mathrm{m}$;

(ii) intra- and inter-tunnel anion ordering that leads to $P 2_{1} / b$ varieties, possible modulation and extension of the (001) basal plane;

(iii) framework topological tuning where the $A_{6}^{T} X_{2}$ tunnel contents are sufficiently small or sub-stoichiometric that the framework must constrict by increasing the $A^{F} \mathrm{O}_{6}$ metaprism twist angle $(\varphi)$ to $>\sim 25^{\circ}$ that is accompanied by a reduction to $P 2_{1} / m, P 2_{1}$ or $P \overline{1}$ symmetry;

(iv) framework hybrid intergrowth in which oxygen superand sub-stoichiometry leads to partial or complete replacement of $B_{4}$ tetrahedra by $B \mathrm{O}_{5}$ and $B \mathrm{O}_{3}$ polyhedra, sometimes accompanied by a reduction in symmetry;

(v) polymorphic transformations initiated by the application of temperature/pressure that changes relative ionic sizes to drive framework tuning;

(vi) pseudomorphism ${ }^{3}$ whereby quite small compositional adjustments lead to breaches in the critical limits of the metaprism twist angle and a change in symmetry; and

(vii) polysomatism that arises by rotational twinning of $A_{5} B_{3} \mathrm{O}_{18} X_{\delta}$ modules in ordered and disordered sequences.

These fundamental crystallographic principles can operate cooperatively, and when apatite phase space is viewed in total it is evident that substantial opportunities exist to formulate new derivatives through the creation of $A_{4}^{F} A_{6}^{T}\left(B \mathrm{O}_{3} / B \mathrm{O}_{4} /\right.$ $\left.B \mathrm{O}_{5}\right)_{6} X_{2}$ hybrids that may display polysomatic character (Fig. 12). Although this study has focused on intergrowth of tetrahedral strings, there is no reason to exclude $B \mathrm{O}_{3} / B \mathrm{O}_{5}$ [001] intergrowths, and preliminary electron diffraction of $\mathrm{Ba}_{10}\left(\mathrm{ReO}_{5}\right)_{6} \mathrm{O}_{2}$ shows diffuse scatter indicative of $(00 l)$ polysome disorder (Pramana \& White, 2009).

\subsection{Future polysome chemistries}

All apatite polysomes reported to date are predominantly plumbous, and it is clear that $\mathrm{Pb}^{2+}$ partitions to the $A^{T}$ sites so that stereochemically active lone-pair electrons stabilize these phases by occupying the volume normally containing $X$ anions. It is therefore intriguing that $\mathrm{Bi}^{3+}$, which also possesses electron lone pairs, partitions to $A^{F}$ positions and does did not play a similar role to $\mathrm{Pb}^{2+}$. This suggests the size difference between $\mathrm{Bi}^{3+}(1.17 \AA)$ and $\mathrm{Pb}^{2+}(1.29 \AA)$ and/or the require-

\footnotetext{
${ }^{3}$ We have chosen the term pseudomorphism in preference to the more cumbersome, but strictly correct, pseudopolymorphism. This crystallographic use of pseudomorphism is distinct from the geological meaning that describes a mineral altered in a manner that preserves the external form but the internal structure and chemical composition is modified.
}

ment for localized charge balance with $\mathrm{Na}^{+}$are overriding factors. However, such analyses are non-trivial as Hyde \& Anderson (1989) suggest the lone-pair distance in $\mathrm{Bi}^{3+}$ $(0.98 \AA)$ is greater than $\mathrm{Pb}^{2+}(0.86 \AA)$, which would a priori favour entry of bismuth in the $A^{T}$ sites. Some clarity could be gained by synthesizing monovalent thallium-bearing polysomes where the $\mathrm{Tl}^{+}$ion is relatively large $(1.59 \AA)$, but its lone-pair distance is short $(0.69 \AA)$. Were $\mathrm{Tl}^{+}$to completely replace $\mathrm{Pb}^{2+}$ in the tunnel, and assuming the $B$ sites are occupied by +4 ions, charge-balance considerations would require the $A^{F}$ sites to have a charge of +3.5 per site, as for example in hypothetical $N=3 \quad\left[\mathrm{Ce}_{3}^{4+} \mathrm{Bi}_{3}^{3+}\right]\left[\mathrm{Tl}_{9}^{+}\right]-$ $\left(\mathrm{Ge}_{2} \mathrm{O}_{7}\right)_{3}\left(\mathrm{GeO}_{4}\right)_{3} \square_{3}$ or $N=4\left[\mathrm{Ce}_{4}^{4+} \mathrm{Bi}_{4}^{3+}\right]\left[\mathrm{Tl}_{12}^{+}\right]\left(\mathrm{Si}_{2} \mathrm{O}_{7}\right)_{6} \mathrm{Cl}_{4}$. However, $\mathrm{Tl}^{+}$may display characteristics similar to a large alkali $\left(e . g . \mathrm{Rb}^{+}\right.$or $\left.\mathrm{Cs}^{+}\right)$and show a strong preference for the $A^{F}$ positions. Clearly, the relative importance of size, charge and stereochemically active lone pairs in limiting polysome chemistry requires further study. Given the extensive chemistries of apatite- $2 S$ polysomes, it would be extraordinary if it proved impossible to formulate new longer period polysomes that are lead free. As noted earlier, several workers have suggested $\mathrm{Ca}_{20}\left(\mathrm{Si}_{2} \mathrm{O}_{7}\right)_{6} \mathrm{Cl}_{2}$ is an $N=4$ polysome (Stemmermann, 1992; Hermoneit et al., 1981; Ye et al., 1986; Ding et al., 2007).

\subsection{Polysomes as functional materials}

Apatite polysomes with identical chemistries, such as ( $\mathrm{Pb} \mathrm{Ge} \square)-2 H,(\mathrm{~Pb} \mathrm{Ge} \square)-3 H$ and ( $\mathrm{Pb} \mathrm{Ge} \square$ )- $4 H$, will display unique physical properties and functionalities. For example, silicate and germanate apatites are promising low-temperature solid-oxide fuel cell electrolytes. Crystallographic (Pramana et al., 2007) and computational (Kendrick et al., 2007) studies suggest that oxide ion mobility is mediated via the $\mathrm{SiO}_{4}$ and $\mathrm{GeO}_{4}$ tetrahedra, and consequently, longerperiod tetrahedral strings that reduce metaprism twisting and expand the primary ion-conducting channel may prove beneficial for ion transport and conductivity (Pramana et al.,

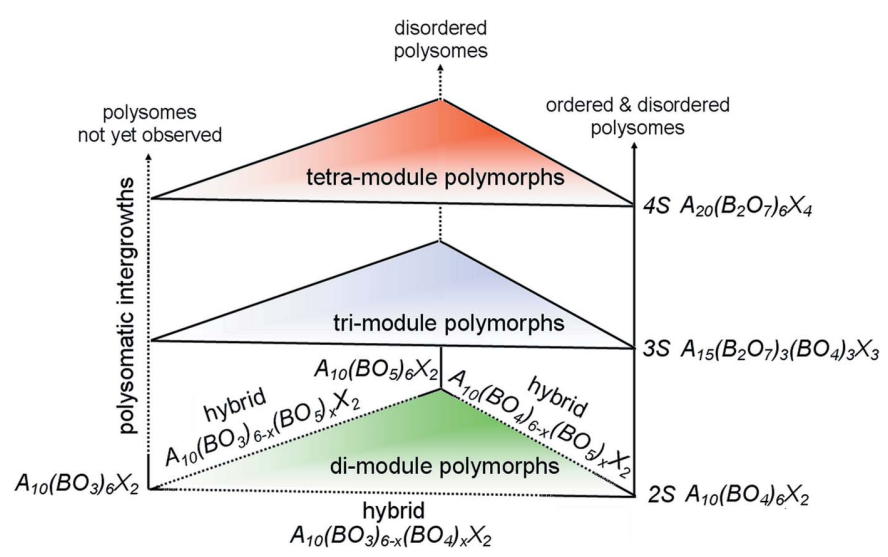

Figure 12

An expanded apatite phase space containing all permutations of polymorphs, pseudomorphs, polysomes and hybrid structures that may be feasible. 
Table 5

Interpretation of silicate apatite electrolytes as ordered polysomes.

Note the conventional representation does not include the $\mathrm{Si}_{2} \mathrm{O}_{7}$ and $\mathrm{Si}_{2} \mathrm{O}_{9}$ entities identified by ${ }^{29} \mathrm{Si}$ NMR.

\begin{tabular}{llll}
\hline Composition & Conventional representation & Polysome representation & $N$ \\
\hline $\mathrm{La}_{9.33} \mathrm{Si}_{6} \mathrm{O}_{26}$ & {$\left[\mathrm{La}_{3.33} \square_{0.67}\right]\left[\mathrm{La}_{6}\right]\left[\left(\mathrm{SiO}_{4}\right)_{6}\right] \mathrm{O}_{2}$} & {$\left[\mathrm{La}_{10} \square_{2}\right]\left[\mathrm{La}_{18}\right]\left[\left(\mathrm{SiO}_{4}\right)_{6}\left(\mathrm{Si}_{2} \mathrm{O}_{9}\right)_{3}\left(\mathrm{Si}_{2} \mathrm{O}_{7}\right)_{3}\right] \mathrm{O}_{6}$} & 6 \\
$\mathrm{La}_{9.67} \mathrm{Si}_{6} \mathrm{O}_{26.5}$ & {$\left[\mathrm{La}_{3.67} \square_{0.33}\right]\left[\mathrm{La}_{6}\right]\left[\left(\mathrm{SiO}_{4}\right)_{6}\right] \mathrm{O}_{2.5}$} & {$\left[\mathrm{La}_{22} \square_{2}\right]\left[\mathrm{La}_{36}\right]\left[\left(\mathrm{SiO}_{4}\right)_{18}\left(\mathrm{Si}_{2} \mathrm{O}_{9}\right)_{6}\left(\mathrm{Si}_{2} \mathrm{O}_{7}\right)_{3}\right] \mathrm{O}_{12}$} & 12 \\
\hline
\end{tabular}

2009). At the very least, measurements of physical properties across polysomatic series can be used to better understand mechanistic features, as used to good effect in the Ruddlesden-Popper homologous series $\left(A_{n+1} B_{n} \mathrm{O}_{3 n+1}\right)$ superconducting cuprates where it was predicted, and observed experimentally, that longer-period polysomes yielded higher high $T_{\mathrm{c}}$ (Skakle, 1998).

Moreover, outstanding questions remain regarding the extensively studied structures of the cation-deficient $\mathrm{La}_{9.33}\left(\mathrm{SiO}_{4}\right)_{6} \mathrm{O}_{2}$ and $\mathrm{La}_{9.67}\left(\mathrm{SiO}_{4}\right)_{6} \mathrm{O}_{2.5}$ apatite electrolytes. Powder neutron-diffraction studies have shown that lowering the symmetry from $P 6_{3} / m$ to $P 6_{3}$ (Tolchard \& Slater, 2008) or $P \overline{3}$ (Sansom et al., 2001) led to improved fits, as the removal of the mirror plane better represented static oxygen disorder. From this study, it can be proposed that the static disorder may be a consequence of polysynthetic twinning on the unit-cell scale that provides a means to accommodate cation vacancies at the La framework sites. These stacking faults would produce cages from $\mathrm{Si}_{2} \mathrm{O}_{7}$ units, as shown in Fig. 13(a), which have already been observed in $\mathrm{Na}_{3} \mathrm{YSi}_{2} \mathrm{O}_{7}$ (Merinov et al., 1981). This proposed structural arrangement is also supported by recent ${ }^{29} \mathrm{Si}$ NMR studies (Sansom et al., 2006; Orera et al., 2008), which show lanthanum silicate apatites containing La vacancies and/or excess oxygen give chemical shifts consistent with $\mathrm{Si}_{2} \mathrm{O}_{7}$ dimers, together with the expected chemical shift for $\mathrm{SiO}_{4}$ units. In addition, chemical shifts for $\mathrm{Si}_{2} \mathrm{O}_{9}$ were found, which would be consistent with oxygen interstitials. In contrast, fully stoichiometric samples show a single Si environment for $\mathrm{SiO}_{4}$ units. It is proposed that $\mathrm{La}_{9.33}\left(\mathrm{SiO}_{4}\right)_{6} \mathrm{O}_{2}$ could be re-expressed as an $N=6$ polysome with the general formula $\left[\mathrm{La}_{10} \square_{2}\right]\left[\mathrm{La}_{18}\right]\left[\left(\mathrm{SiO}_{4}\right)_{6}\left(\mathrm{Si}_{2} \mathrm{O}_{9}\right)_{3}\left(\mathrm{Si}_{2} \mathrm{O}_{7}\right)_{3}\right] \mathrm{O}_{6}$ (Table 5). In this idealized structure the La vacancies occur at every sixth stacking layer (Fig. 13b), and while structural studies thus far are consistent with a disordered apatite- $2 \mathrm{H}$ average structure, it may be that the powdered samples and single crystals were not equilibrated. In other apatite systems (Dong \& White, $2004 a, b$ ) and in $\mathrm{La}-\mathrm{Si}-\mathrm{O}$ apatites (Li et al., 2009) several weeks annealing were required to stabilize vacancy sequences. Similarly $\mathrm{La}_{9.67}\left(\mathrm{SiO}_{4}\right)_{6} \mathrm{O}_{2.5}$ could be expressed as an $N=12$ polysome with the formula $\left[\mathrm{La}_{22} \square_{2}\right]\left[\mathrm{La}_{36}\right]\left[\left(\mathrm{SiO}_{4}\right)_{18}\left(\mathrm{Si}_{2} \mathrm{O}_{9}\right)_{6}(-\right.$ $\left.\left.\mathrm{Si}_{2} \mathrm{O}_{7}\right)_{3}\right] \mathrm{O}_{12}$. The principle of describing apatite non-stoichiometry as polysome intergrowths is general and, for example, the cation-deficient hybrid phosphate apatite $\left[\mathrm{Ca}_{9} \mathrm{Na}_{0.5}\right][(-$ $\left.\left.\mathrm{PO}_{4}\right)_{4.5}\left(\mathrm{CO}_{3}\right)_{1.5}\right](\mathrm{OH})_{2}$ might be formally described as an $N=8$ polysome of the type $\left[\mathrm{Ca}_{12} \mathrm{Na}_{2} \square_{2}\right]\left[\mathrm{Ca}_{24}\right]\left[\left(\mathrm{PO}_{4}\right)_{6}\right.$ $\left.\left(\mathrm{CO}_{3}\right)_{6}\left(\mathrm{P}_{2} \mathrm{O}_{9}\right)_{3}\left(\mathrm{P}_{2} \mathrm{O}_{7}\right)_{3}\right](\mathrm{OH})_{8}$. In this case, future ${ }^{31} \mathrm{P}$ MASNMR may shed light on the correctness of this proposed structure where three distinct phosphorus environments are expected.

Although 'apatites' are important biomaterials their precise nature remains speculative because the chemistry is incompletely defined (especially the role of protons; Pasteris et al., 2004), the crystallinity may be poor or they appear as multiphase assemblages. It is believed that amorphous calcium phosphate (ACP) is a precursor of hydroxyapatite and the mechanism of transformation is presumed via an intermediate $\mathrm{Ca}_{2} \mathrm{P}_{2} \mathrm{O}_{7}$ pyrophosphate on the basis of ${ }^{31} \mathrm{P}$ NMR that revealed $\mathrm{P}_{2} \mathrm{O}_{7}$ units (Tropp et al., 1983). However, $\mathrm{P}_{2} \mathrm{O}_{7}$ groups are also consistent with disordered polysome fragments. In other developments, apatites are seen as low temperature and selective catalysts for a range of reactions including $\mathrm{CO}$ oxidation (Matsumura et al., 1997) and volatile organic combustion (VOC; Matsumura et al., 1994). In the latter case, where apatite-( $\mathrm{Ca} \mathrm{POH})-2 \mathrm{H}$ has been used to destroy formaldehyde (HCHO), it is believed that $\mathrm{Ca}^{T}$ and $\mathrm{OH}^{-}$ proximity are critical to promoting the adsorption/activation

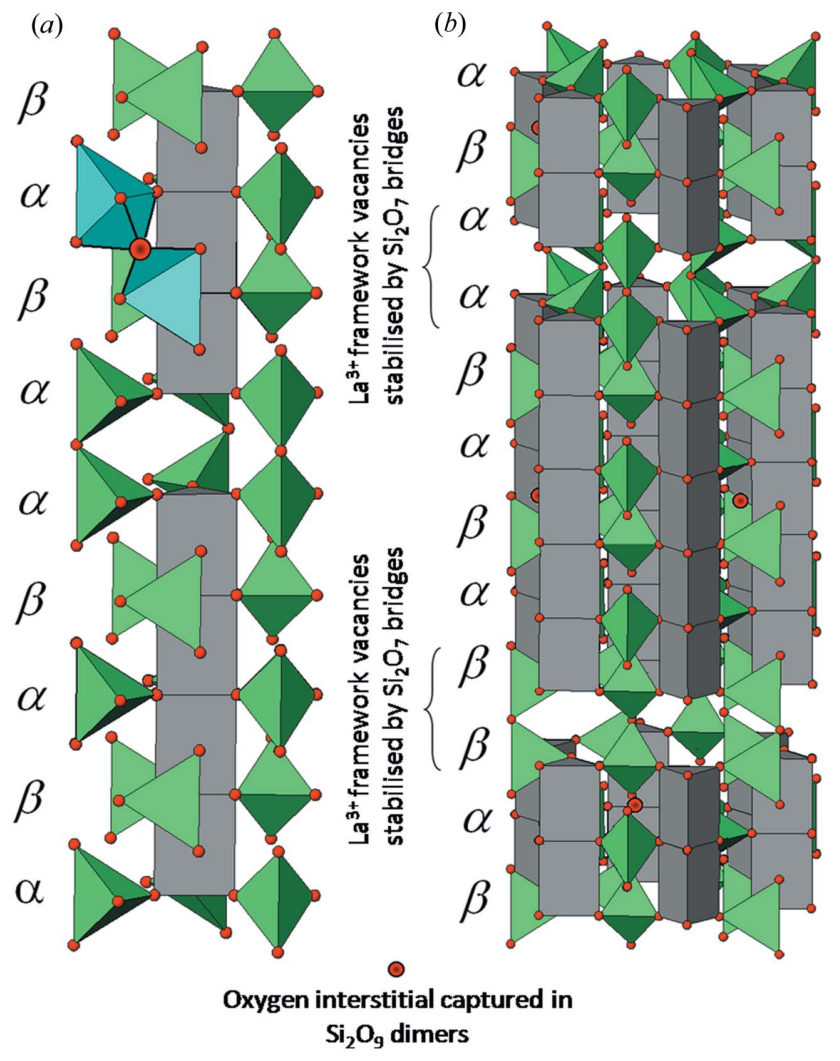

Figure 13

(a) Postulated topology of $\mathrm{Si}_{2} \mathrm{O}_{7}$ constructed cages surrounding $\mathrm{La}^{3+}$ vacancies in the $\mathrm{LaO}_{6}$ prismatic columns of lanthanum silicate oxyapatite electrolytes. Also indicated in blue are $\mathrm{Si}_{2} \mathrm{O}_{9}$ dimers, which can be formed with interstitial oxygen ions. (b) Idealized, and to date hypothetical, $\left[\mathrm{La}_{10} \square_{2}\right]\left[\mathrm{La}_{18}\right]\left[\left(\mathrm{Si}_{2} \mathrm{O}_{7}\right)_{3}\left(\mathrm{Si}_{2} \mathrm{O}_{9}\right)_{3}\left(\mathrm{SiO}_{4}\right)_{6}\right] \mathrm{O}_{6}$ structural arrangement in equilibrated $\mathrm{La}_{9.33} \mathrm{Si}_{6} \mathrm{O}_{26}$, where the $\mathrm{La}^{3+}$ vacancies condense as $\mathrm{Si}_{2} \mathrm{O}_{7}$ cages $(\alpha \alpha)$, with interstitial oxygen ions between some $(\alpha \beta)$ boundaries, to create an $N=6$ polysome. 
of HCHO. It has been suggested that oxygen absorption may be enhanced by replacement of $\mathrm{Ca}^{2+}$ and $\mathrm{P}^{5+}$ by $\mathrm{Ce}^{4+}$ and $\mathrm{Si}^{4+}$, that may favour the creation of $\mathrm{Si}_{n} \mathrm{O}_{3 n+1}$ polysome domains. While our understanding of the technological applications of polysomes is rudimentary, we believe the demonstration of module building principles is sufficiently compelling to warrant their consideration in the design of apatite-based advanced materials.

\section{Conclusions}

A formal description of apatite $A_{5 N} B_{3 N} \mathrm{O}_{9 N+6} X_{N \delta}(2 \leq N \leq$ $\infty)$ polysomes has been developed in which $A_{2}^{F} A_{3}^{T} B_{3} \mathrm{O}_{18} X_{\delta}$ moduless are arranged by $60^{\circ}$ rotation twinning to generate long-period structures. This group of compounds has not received significant attention, although the $N=3$ germanate polysome displays useful ferro- and pyroelectric properties. It is probable that the chemistry of $N>2$ compounds is substantially broader than currently recognized. Electron microscopy has recorded disordered intergrowths of the apatite modules, demonstrating that these are stable structure building entities, rather than abstract crystallographic constructs. As with all polysomatic families, these structural units can be arranged with distinct chemistries, that in apatites controls the relative size of the $\left(A_{2}^{F}\left(B \mathrm{O}_{4}\right)_{3}\right)$ framework with respect to the $A_{3}^{T} X_{\delta}$ tunnel contents, leading to systematic adjustments of the $A^{F} \mathrm{O}_{6}$ metaprism twist angles $(\varphi)$, which ultimately control channel diameter and polysome symmetry. Furthermore, oxidized and reduced varieties exist where $B \mathrm{O}_{4}$ tetrahedra are replaced by $B \mathrm{O}_{5}$ and $B \mathrm{O}_{3}$ entities. With this range of adjustable parameters to hand, it will be feasible to tune and optimize a variety of functionalities including electrical properties, ion conduction, radiation resistance and repair, cation and anion exchange, and magnetic susceptibility amongst others. Nonetheless, exploiting this expanded apatite phase space will not be without challenges. For example, it was found here that polysome powders are often multiphase assemblages of chemically differentiated structural analogues, as observed in ganomalite- $(\mathrm{Pb} \mathrm{Ge} / \mathrm{Si} \square)-3 T$. Designing enhanced synthesis methods that intimately mix constituents to promote rapid equilibration will be a prerequisite to the development of apatite polysomes as practical functional materials.

The authors would like to thank Fui Ling Lew and Yu Yan Liang for sample preparation and the Rutherford Appleton Laboratory for access to neutron beam time. In addition, the authors gratefully acknowledge Professor Stefan Merlino (University of Pisa) for useful discussion regarding silicate framework topologies. This work was funded by A*STAR SERC Grant 'Optimization of Oxygen Sublattices in Solid Oxide Fuel Cell Apatite Electrolytes’ number 0821010021.

\section{References}

Alberius Henning, P., Lidin, S. \& Petříček, V. (1999). Acta Cryst. B55, $165-169$.
Alberius-Henning, P. A., Moustiakimov, M. \& Lidin, S. (2000). J. Solid State Chem. 150, 154-158.

Aminoff, G. (1916). Geol. För. Förh. 38, 473.

Baikie, T., Ferraris, C., Klooster, W. T., Madhavi, S., Pramana, S. S., Pring, A., Schmidt, G. \& White, T. J. (2008). Acta Cryst. B64, 34-41.

Baikie, T., Mercier, P. H. J., Elcombe, M. M., Kim, J. Y., Le Page, Y., Mitchell, L. D., White, T. J. \& Whitfield, P. S. (2007). Acta Cryst. B63, 251-256.

Baikie, T., Ng, M. H. G., Madhavi, S., Pramana, S. S., Blake, K., Elcombe, M. \& White, T. J. (2009). Dalton Trans. pp. 6722-6726.

Bauer, M. \& Klee, W. E. (1993). Z. Kristallogr. 206, 15-24.

Besse, J.-P., Baud, G., Levasseur, G. \& Chevalier, R. (1979). Acta Cryst. B35, 1756-1759.

Brès, E. F., Waddington, W. G., Hutchison, J. L., Cohen, S., Mayer, I. \& Voegel, J.-C. (1987). Acta Cryst. B43, 171-174.

Bruker (2008). TOPAS, Version 4.1. Bruker AXS Inc., Madison, Wisconsin, USA.

Calos, N. J. \& Kennard, C. H. L. (1990). Z. Kristallogr. 191, 125-129.

Carlson, S., Norrestam, R., Holstam, D. \& Spengler, R. (1997). Z. Kristallogr. 212, 208-212.

Cheary, R. W. \& Coelho, A. (1992). J. Appl. Cryst. 25, 109-121.

Cheary, R. W. \& Coelho, A. A. (1998). J. Appl. Cryst. 31, 851-861.

Choudhary, R. N. P. \& Misra, N. K. (1998). J. Phys. Chem. Solids, 59, 605-610.

Dai, Y. S. \& Hughes, J. M. (1989). Can. Mineral. 27, 189-192.

Ding, W., Wang, J., Zhang, M., Zhang, Q. \& Su, Q. (2007). Chem. Phys. Lett. 435, 301-305.

Dong, Z.-L. \& White, T. J. (2004a). Acta Cryst. B60, 138-145.

Dong, Z.-L. \& White, T. J. (2004b). Acta Cryst. B60, 146-154.

Dunn, P. J., Peacor, D. R. P., Valley, J. W. \& Randall, C. A. (1985). Mineral. Mag. 49, 579-582.

Elliott, J. C., Mackie, P. E. \& Young, R. A. (1973). Science, 180, 1055 1057.

Engel, G. (1972). Naturwissenschaften, 59, 121-122.

Engel, G. \& Deppisch, B. (1988). Z. Anorg. Allg. Chem. 562, 131-140.

Eysel, W., Wolfe, R. W. \& Newnham, R. E. (1973). J. Am. Ceram. Soc. 56, 185-188.

Feki, H. E., Savariault, J. M. \& Salah, A. B. (1999). J. Alloy Compd. 287, 114-120.

Ferraris, C., White, T. J., Plevert, J. \& Wegner, R. (2005). Phys. Chem. Miner. 32, 485-492.

Frondel, C. \& Bauer, L. H. (1951). Am. Mineral. 36, 534.

Giuseppetti, G., Rossi, G. \& Tadini, C. (1971). Am. Mineral. 56, 1174 1179.

Goswami, N. M. L., Choudhary, R. N. P., Acharya, H. N. \& Mahapatra, P. K. (2001). J. Phys. D Appl. Phys. 34, 389-394.

Goswami, N. M. L., Choudhary, R. N. P. \& Mahapatra, P. K. (1997). Chem. Phys. Lett. 278, 365-368.

Goswami, N. M. L., Choudhary, R. N. P. \& Mahapatra, P. K. (1998a). Ferroelectrics, 216, 1-10.

Goswami, N. M. L., Choudhary, R. N. P. \& Mahapatra, P. K. (1998b). J. Phys. Chem. Solids, 59, 1045-1052.

Goswami, N. M. L., Mahapatra, P. K. \& Choudhary, R. N. P. (1998). Mater. Lett. 35, 329-333.

Hamdi, B., El Feki, H., Savariault, J.-M. \& Salah, A. B. (2007). Mater. Res. Bull. 42, 299-311.

Hamdi, B., Savariault, J.-M., El Feki, H. \& Ben Salah, A. (2004). Acta Cryst. C60, i1-i2.

Hasegawa, H., Shimada, M., Kanamaru, F. \& Koizumi, M. (1977). Bull. Chem. Soc. Jpn, 50, 529.

Hermoneit, B., Ziemer, B. \& Malewski, G. (1981). J. Cryst. Growth, 52, 660-664.

Hughes, J. M., Cameron, M. \& Crowley, K. D. (1989). Am. Mineral. 74, 870-876.

Hyde, B. G. \& Anderson, S. (1989). Inorganic Crystal Structures. New York: John Wiley.

Hyde, B. G., Andersson, S., Bakker, M., Plug, C. M. \& O'Keeffe, M. (1979). Prog. Solid State Chem. 12, 273-327. 
Ireland, T. R. (1990). Geochim. Cosmochim. Acta, 54, 3219-3237.

Ivanov, S. A. (1990). J. Struct. Chem. 31, 80-84.

Iwasaki, H., Miyazawa, S., Koizumi, H., Sugii, K. \& Niizeki, N. (1972). J. Appl. Phys. 43, 4907-4915.

Iwasaki, H., Sugii, K., Niizeki, N. \& Toyoda, H. (1972). Ferroelectrics, 3, 157-161.

Iwasaki, H., Sugii, K., Yamada, T. \& Niizeki, N. (1971). Phys. Lett. 18, 444-445.

Iwata, Y. (1977). J. Phys. Soc. Jpn, 43, 961-967.

Iwata, Y., Koizumi, H., Koyano, N., Shibuya, I. \& Niizeki, N. (1973). J. Phys. Soc. Jpn, 35, 314.

Kay, M. I., Newnham, R. E. \& Wolfe, R. W. (1975). Ferroelectrics, 9, $1-6$.

Kazin, P. E., Garizova Olga, R., Karpov, A. S., Jansen, M. \& Tretyakov, Y. D. (2007). Solid State Sci. 1, 82-87.

Kazin, P. E., Karpov, A. S., Jansen, M., Nuss, J. \& Tretyakov, Y. D. (2003). Z. Anorg. Allg. Chem. 629, 344-352.

Kendrick, E., Islam, M. S. \& Slater, P. R. (2007). J. Mater. Chem. 17, 3104-3111.

Krivovichev, S. V., Armbruster, T. \& Depmeier, W. (2004). Mater. Res. Bull. 39, 1717-1722.

Larson, A. C. \& Von Dreele, R. B. (1987). GSAS, Report LAUR 86748. Los Alamos National Laboratory, New Mexico, USA.

Leonyuk, L., Babonas, G.-J., Maltsev, V. \& Rybakov, V. (1999). Acta Cryst. A55, 628-634.

Li, H., Baikie, T. \& White, T. J. (2009). Personal communication.

Lutze, W. \& Ewing, R. C. (1988). Radioactive Waste Forms for the Future. Amsterdam: North-Holland.

Mackie, P. E., Elliot, J. C. \& Young, R. A. (1972). Acta Cryst. B28, 1840-1848.

Malinovskii, Y. A., Genekina, E. A. \& Dimitrova, O. V. (1990). Kristallografiya, 35, 328-331.

Manecki, M., Maurice, P. A. \& Traina, S. J. (2000). Am. Mineral. 85, 932-942.

Matsumura, Y., Kanai, H. \& Moffat, J. B. (1997). J. Chem. Soc. Faraday Trans. 93, 4383-4387.

Matsumura, Y., Sugiyama, S., Hayashi, H., Shigemota, N., Saitoh, K. \& Moffat, J. B. (1994). J. Mol. Catal. 92, 81-94.

Mellini, M., Trommsdorff, V. \& Compagnoni, R. (1987). Contrib. Mineral. Petrol. 97, 147-155.

Merinov, B. V., Maksimov, B. A. \& Belov, N. V. (1981). Dokl. Akad. Nauk SSSR, 260, 1128-1130.

Misra, N. K., Choudhary, R. N. P. \& Sati, R. (1998). Ferroelectrics, 207, 527-539.

Misra, N. K., Sati, R. \& Choudary, R. N. P. (1995). Mater. Lett. 24, $313-$ 317.

Misra, N. K., Sati, R. \& Choudhary, R. N. P. (1999). J. Phys. Chem. Solids, 60, 1967-1972.

Nakayama, S., Kagayama, T., Aono, H. \& Sadoaka, Y. (1995). J. Mater. Chem. 5, 1801-1806.

Nanamatsu, S., Sugiyama, H., Dol, K. \& Konda, Y. (1971). J. Phys. Soc. Jpn, 31, 616.

Naray-Szabo, S. (1930). Z. Kristallogr. 75, 387-398.

Nassau, K., Shiever, J. W., Joy, D. C. \& Glass, A. M. (1977). J. Cryst. Growth, 42, 574-578.

Newnham, R. E., Wolfe, R. W. \& Darlington, C. N. W. (1973). J. Solid State Chem. 6, 378-383.

Nickel, E. H. \& Mandarino, J. A. (1987). Can. Mineral. 25, 353-377. Nittler, L. R. (2003). Earth Planet. Sci. Lett. 209, 259-273.

Nordenskiöld, A. E. (1876). Geol. För. Stock För. 3, 121.

Nordenskiöld, A. E. (1877). Geol. För. Stock För. 3, 376-384.

O'Keeffe, M. \& Hyde, B. G. (1985). Struct. Bonding, 61, 79-144.

Orera, A., Kendrick, E., Apperley, D. C., Orera, V. M. \& Slater, P. R. (2008). Dalton Trans. pp. 5296-5301.
Otto, H. H. \& Loster, P. (1993). Ferroelectr. Lett. 16, 81-86.

Otto, H. H., Stock, M., Gebhardt, W. \& Polomska, M. (1980). Ferroelectrics, 25, 543-546.

Palache, C. (1935). US Geol. Surv., Prof. Paper 180, 92.

Pan, Y. \& Fleet, M. E. (2002). Rev. Miner. Geochem. pp. 13-49.

Park, C. \& Snyder, R. L. (1995). Appl. Supercond. 3, 73-83.

Pasero, M., Kampf, A. R., Ferraris, C., Pekov, I. V., Rakovan, J. F. \& White, T. J. (2010). Eur. J. Mineral. In the press.

Pasteris, J. D., Wopenka, B., Freeman, J. J., Rogers, K., Valsami-Jones, E., Van der Houwen, J. A. M. \& Silva, M. J. (2004). Biomaterials, 25, 229-238.

Payne, S. A., DeLoach, L. D., Smith, L. K., Kway, W. L., Tassano, J. B., Krupke, W. F., Chai, B. H. T. \& Loutts, G. (1994). J. Appl. Phys. 76, 497-503.

Penfield, S. L. \& Warren, C. H. (1899). Am. J. Sci. 8, 339.

Piccoli, P. M. \& Candela, P. A. (2002). Rev. Miner. Geochem. 48, 255292.

Povarennykh, A. S. (1972). Crystal Chemical Classification of Minerals. New York: Plenum Press.

Pramana, S. S., Klooster, W. T. \& White, T. J. (2007). Acta Cryst. B63, 597-602.

Pramana, S. S., Klooster, W. T. \& White, T. J. (2008). J. Solid State Chem. 181, 1717-1722.

Pramana, S. S. \& White, T. J. (2009). Personal communication.

Pramana, S. S., White, T. J., Schreyer, M. K., Ferraris, C., Slater, P. R., Orera, A., Bastow, T. J., Mangold, S., Doyle, S., Liu, T., Fajar, A., Srinivasan, M. \& Baikie, T. (2009). Dalton Trans. pp. 8280-8291.

Rouse, R. C., Dunn, P. J. \& Peacor, D. R. (1984). Am. Mineral. 89, 920-927.

Sansom, J. E. H., Richings, D. \& Slater, P. R. (2001). Solid State Ion. 139, 205-210.

Sansom, J. E. H., Tolchard, J. R., Islam, M. S., Apperley, D. \& Slater, P. R. (2006). J. Mater. Chem. 16, 1410-1413.

Shannon, R. D. (1976). Acta Cryst. A32, 751-767.

Skakle, J. M. S. (1998). Mater. Sci. Eng. Rep. 23, 1-40.

Stadelmann, P. (2003). JEMS, 12M-EPFL, CH-1015 Lausanne, Switzerland.

Stemmermann, P. (1992). PhD thesis. Freidrich-Alexander-Universität.

Thompson Jr, J. B. (1978). Am. Miner. 55, 239-249.

Tolchard, J. R. \& Slater, P. R. (2008). J. Phys. Chem. Solids, 69, $2433-$ 2439.

Tropp, J., Blumenthal, N. C. \& Waugh, J. S. (1983). J. Am. Chem. Soc. 105, 22-26.

Veblen, D. R. (1991). Am. Miner. 76, 801-826.

Wazalwar, A. V. \& Katpatal, A. G. (2001). J. Phys. Chem. Solids, 63, $1633-1638$

Wazalwar, A. V. \& Katpatal, A. G. (2002). Mater. Lett. 55, 221-229.

Weiner, S. \& Wagner, H. D. (1998). Ann. Rev. Mater. Sci. 28, 271298.

White, T. J., Ferraris, C., Kim, J. \& Madhavi, S. (2005). Rev. Miner. Geochem. 57, 307.

White, T. J., Segall, R. L. \& Turner, P. S. (1985). Angew. Chem. Int. Ed. 24, 357-365.

White, T. J. \& ZhiLi, D. (2003). Acta Cryst. B59, 1-16.

Wu, X., Xu, Y., Xiao, J., Wu, A. \& Jin, W. (2004). J. Cryst. Growth, 263, 208-213.

Wyckoff, R. W. G. (1965). Inorganic compounds $R_{x}\left(M X_{4}\right)_{y}$, $R_{x}\left(M n X_{p}\right)_{y}$, Hydrates and Ammoniates. New York: John Wiley and Sons.

Yao, Y. F. Y. \& Kiemmer, J. T. (1967). J. Inorg. Nucl. Chem. 29, $2453-$ 2466.

Ye, R. L., Wu, B. L., Zeng, K. \& Zhang, Z. Y. (1986). Guisuanyan Xuebao, 14, 183. 